\title{
Blockade of individual Notch ligands and receptors controls graft-versus-host disease
}

\author{
Ivy T. Tran, ${ }^{1}$ Ashley R. Sandy, ${ }^{1,2}$ Alexis J. Carulli, ${ }^{3}$ Christen Ebens, ${ }^{1,4}$ \\ Jooho Chung, ${ }^{1,5}$ Gloria T. Shan, ${ }^{1}$ Vedran Radojcic, ${ }^{1,6}$ Ann Friedman, ${ }^{1}$ \\ Thomas Gridley, ${ }^{7}$ Amy Shelton, ${ }^{8}$ Pavan Reddy, ${ }^{6}$ Linda C. Samuelson, ${ }^{3,9}$ \\ Minhong Yan, ${ }^{10}$ Christian W. Siebel, ${ }^{8}$ and Ivan Maillard ${ }^{1,6,11}$
}

\begin{abstract}
${ }^{1}$ Life Sciences Institute, ${ }^{2}$ Graduate Program of Immunology, ${ }^{3}$ Department of Molecular and Integrative Physiology, ${ }^{4}$ Department of Pediatrics, ${ }^{5}$ Graduate Program of Cellular and Molecular Biology, and ${ }^{6}$ Department of Internal Medicine, Division of Hematology-Oncology, University of Michigan, Ann Arbor, Michigan, USA. ${ }^{7}$ Center for Molecular Medicine, Maine Medical Center Research Institute, Scarborough, Maine, USA. ${ }^{8}$ Department of Molecular Biology, Genentech Inc., South San Francisco, California, USA. ${ }^{9}$ Department of Internal Medicine, Division of Gastroenterology, University of Michigan, Ann Arbor, Michigan, USA. ${ }^{10}$ Department of Tumor Biology and Angiogenesis, Genentech Inc., South San Francisco, California, USA. 11Department of Cell and Developmental Biology, University of Michigan, Ann Arbor, Michigan, USA
\end{abstract}

\begin{abstract}
Graft-versus-host disease (GVHD) is the main complication of allogeneic bone marrow transplantation. Current strategies to control GVHD rely on global immunosuppression. These strategies are incompletely effective and decrease the anticancer activity of the allogeneic graft. We previously identified Notch signaling in $T$ cells as a new therapeutic target for preventing GVHD. Notch-deprived $T$ cells showed markedly decreased production of inflammatory cytokines, but normal in vivo proliferation, increased accumulation of regulatory $T$ cells, and preserved anticancer effects. Here, we report that $\gamma$-secretase inhibitors can block all Notch signals in alloreactive $\mathrm{T}$ cells, but lead to severe on-target intestinal toxicity. Using newly developed humanized antibodies and conditional genetic models, we demonstrate that Notch1/Notch2 receptors and the Notch ligands Delta-like1/4 mediate all the effects of Notch signaling in T cells during GVHD, with dominant roles for Notch1 and Delta-like4. Notch1 inhibition controlled GVHD, but led to treatment-limiting toxicity. In contrast, Delta-like1/4 inhibition blocked GVHD without limiting adverse effects while preserving substantial anticancer activity. Transient blockade in the peritransplant period provided durable protection. These findings open new perspectives for selective and safe targeting of individual Notch pathway components in GVHD and other $\mathrm{T}$ cell-mediated human disorders.
\end{abstract}

\section{Introduction}

Allogeneic BM or hematopoietic cell transplantation (allo-BMT) is an essential therapeutic modality for patients with hematological malignancies and other blood disorders. In cancer patients, beneficial effects of allo-BMT are based on immune-mediated elimination of tumor cells due to the graft-versus-tumor (GVT) activity of donor T cells (1-3). Unfortunately, T cells also mediate damage to normal host tissues, leading to graft-versus-host disease (GVHD) $(1,4,5)$. GVHD remains the most devastating complication of allo-BMT, with high mortality, morbidity, and healthcare costs. Current strategies to control GVHD involve T cell depletion from the graft or global immunosuppression $(5,6)$. Despite these interventions, acute and chronic GVHD still arise in many allo-BMT patients $(5,7)$. In addition, immunosuppression decreases GVT efficiency, leading to increased rates of cancer relapse $(1,8)$. Thus, new approaches are needed to prevent GVHD without eliminating GVT activity in allo-BMT recipients.

We have discovered a critical role for Notch signaling in pathogenic host-reactive T cells after allo-BMT (9). Notch is a cell-cell communication pathway with multiple functions in health and disease $(10,11)$. Notch ligands of the Delta-like (Dll1, Dll3, Dll4) or Jagged (Jagged1, Jagged2) family interact with one of 4 mammalian Notch receptors (Notch1-4), leading to proteolytic receptor

Conflict of interest: Amy Shelton, Minhong Yan, and Christian W. Siebel are employed by Genentech Inc.

Citation for this article: J Clin Invest. 2013;123(4):1590-1604. doi:10.1172/JCI65477. activation by $\gamma$-secretase (10). In the hematopoietic system, Notch plays an essential role in early $\mathrm{T}$ cell development (12-15). Moreover, emerging work has identified Notch functions in mature $\mathrm{T}$ cell immunity (16-19). To assess the overall effects of Notch signaling in T cells after allo-BMT, we conditionally expressed a dominant negative Mastermind-like (DNMAML) pan-Notch inhibitor in mature $\mathrm{CD}^{+}$and $\mathrm{CD}^{+} \mathrm{T}$ cells $(9,20)$. DNMAML is a truncated fragment of the Mastermind-like1 coactivator fused to GFP that blocks transcriptional activation downstream of all Notch receptors (20-23). DNMAML expression in donor T cells led to markedly reduced GVHD severity, without causing global immunosuppression (9). DNMAML alloreactive T cells displayed decreased production of multiple inflammatory cytokines and increased expansion of Tregs, leading to reduced target organ damage. However, DNMAML T cells proliferated and expanded in vivo as well, or even better, than WT alloreactive T cells. Importantly, DNMAML T cells retained potent cytotoxic potential and GVT activity, as recipients of DNMAML T cells were able to overcome a leukemia challenge. This led to long-term survival of allo-BMT recipients, free of leukemia and severe GVHD. Our findings identify Notch signaling in donor $\mathrm{T}$ cells as an attractive target for achieving beneficial immunomodulation and inhibiting GVHD after allo-BMT.

Although genetic strategies are invaluable in studying the role of Notch signaling in disease models, pharmacological interventions are required to harness the therapeutic potential of Notch inhibition (24). Here, we report that $\gamma$-secretase inhibitors (GSIs) blocked Notch signaling in alloreactive 
A

$$
\begin{gathered}
\text { WT B6 T cells } \\
+ \\
\text { Vehicle i.p. }
\end{gathered}
$$$$
\begin{aligned}
\mathrm{B} 6 & \rightarrow \mathrm{BALB} / \mathrm{C} \\
\text { Day } 5 \text { donor } \mathrm{CD} 4^{+} &
\end{aligned}
$$$$
\mathrm{CD}^{+} \mathrm{T} \text { cells }
$$
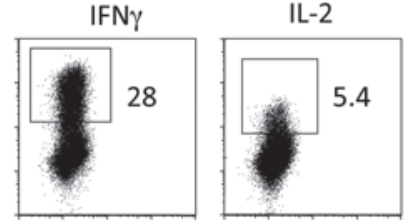

$$
\begin{gathered}
\text { WT B6 T cells } \\
+ \\
\text { DBZ i.p. }
\end{gathered}
$$

\section{DNMAML} B6 T cells

$+$

Vehicle i.p.
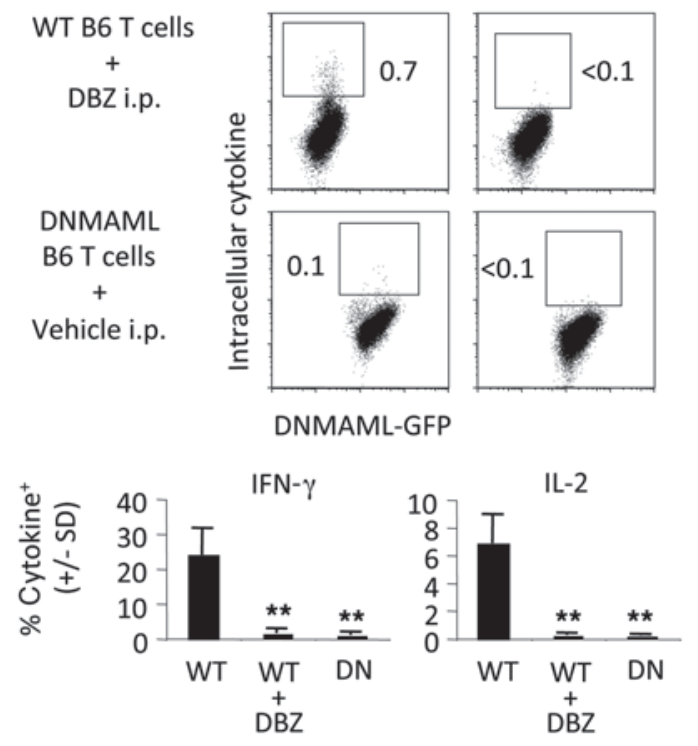

D

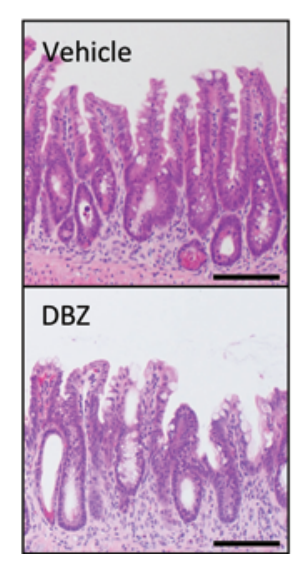

B

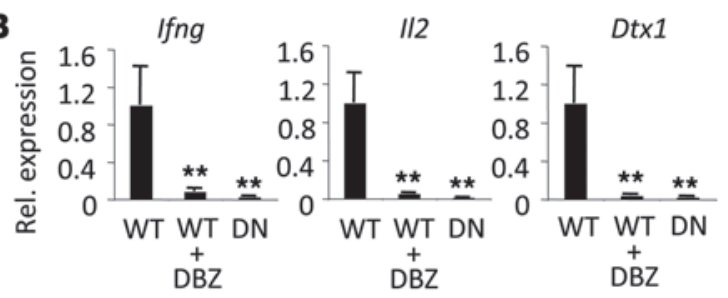

C

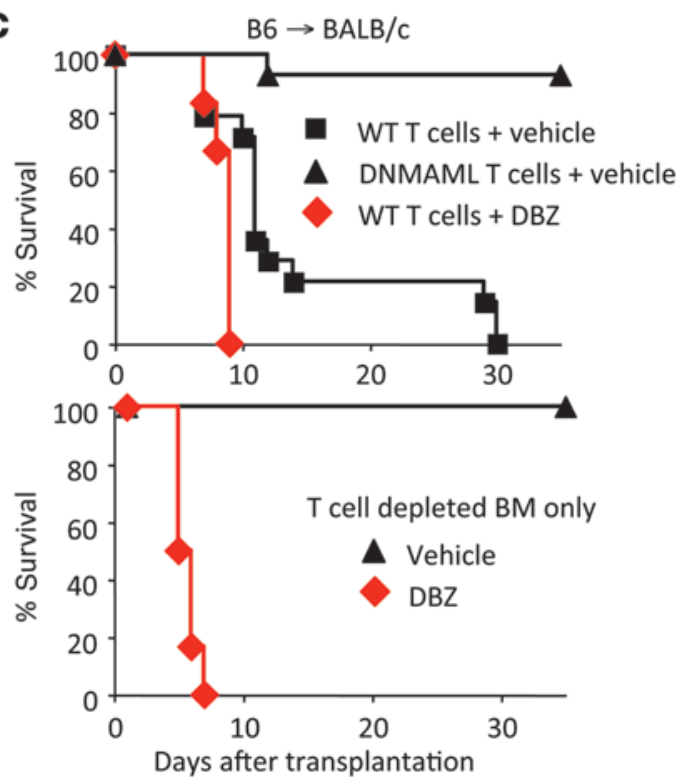

E

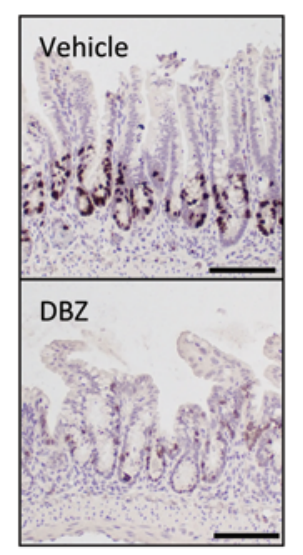

$\#$ BrdU+ cells/crypt

(+/-SD)

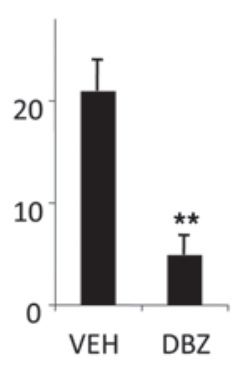

\section{Figure 1}

Efficient Notch inhibition in alloreactive T cells but severe intestinal toxicity of GSIs after BM transplantation. Lethally irradiated (9 Gy) BALB/c mice were transplanted with B6 TCD BM $\left(5 \times 10^{6}\right.$ cells) with or without WT or DNMAML (DN) B6 T cells $\left(10 \times 10^{6}\right.$ splenocytes). The GSI DBZ was administered daily as compared with vehicle (i.p., $10 \mu \mathrm{mol} / \mathrm{kg}$ ) (28). (A) Cytokine production by donor-derived H2Kb+H2Kd- CD4+ spleen T cells at day 5 after alloBMT. Representative flow cytometry plots show intracellular IFN- $\gamma$ and IL-2 after anti-CD3/CD28 restimulation. (B) Relative abundance of transcripts for Ifng, II2, and the Notch target gene Dtx1 in day-5 donor-derived CD4+ $T$ cells after anti-CD3/CD28 restimulation. (C) Short survival of DBZ-treated mice after allo-BMT, even upon transplantation of TCD BM only $(P<0.01$, WT vehicle vs. WT DBZ; $P<0.0001$, TCD vehicle vs. TCD DBZ). In contrast, DNMAML expression in donor T cells led to markedly prolonged survival $(P<0.0001$, WT vs. DNMAML vehicle) $(n=14$ for vehicle-treated, $n=6$ for DBZ-treated groups). (D) H\&E sections and quantification of villus atrophy in the ileum of DBZ-treated mice at day 5 after allo-BMT ( $n=5-6 / g r o u p$ ). (E) Markedly decreased BrdU incorporation upon DBZ treatment $\left(n=3\right.$ /group). Scale bars: $100 \mu \mathrm{m}$. Bar graphs represent mean \pm SD. ${ }^{* *} P<0.01$.

T cells during GVHD, but led to severe on-target side effects in the intestinal epithelium after allo-BMT. To bypass this limiting toxicity, we targeted individual Notch ligands and receptors in mice using newly developed potent and specific neutralizing humanized monoclonal antibodies $(24,25)$. These antibodies block both mouse and human proteins $(24,25)$. We found that Notch $1 / 2$ and Dll1/4 accounted for all the effects of Notch signaling in alloreactive $\mathrm{T}$ cells, with dominant effects for Notch1 
A
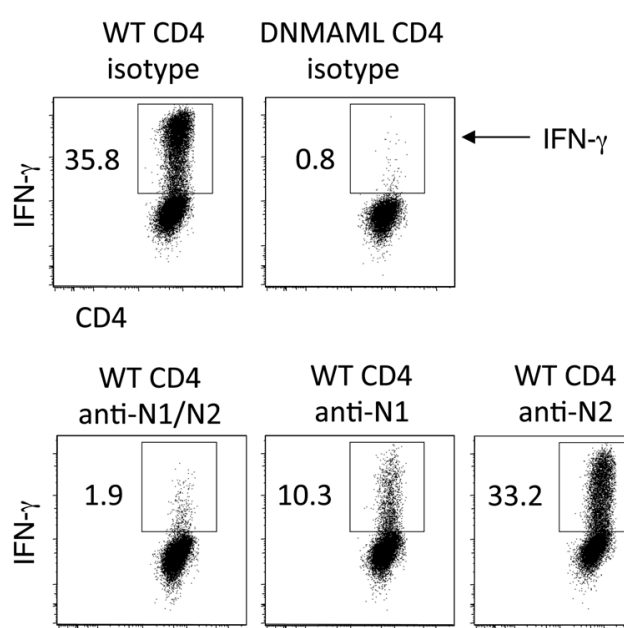

CD4
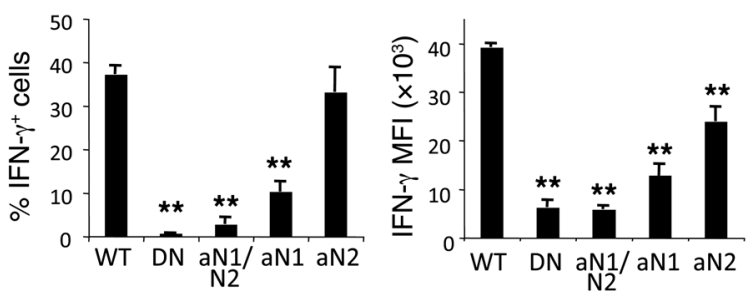

B

Day 5 donor $\mathrm{CD} 4^{+} \mathrm{T}$ cells
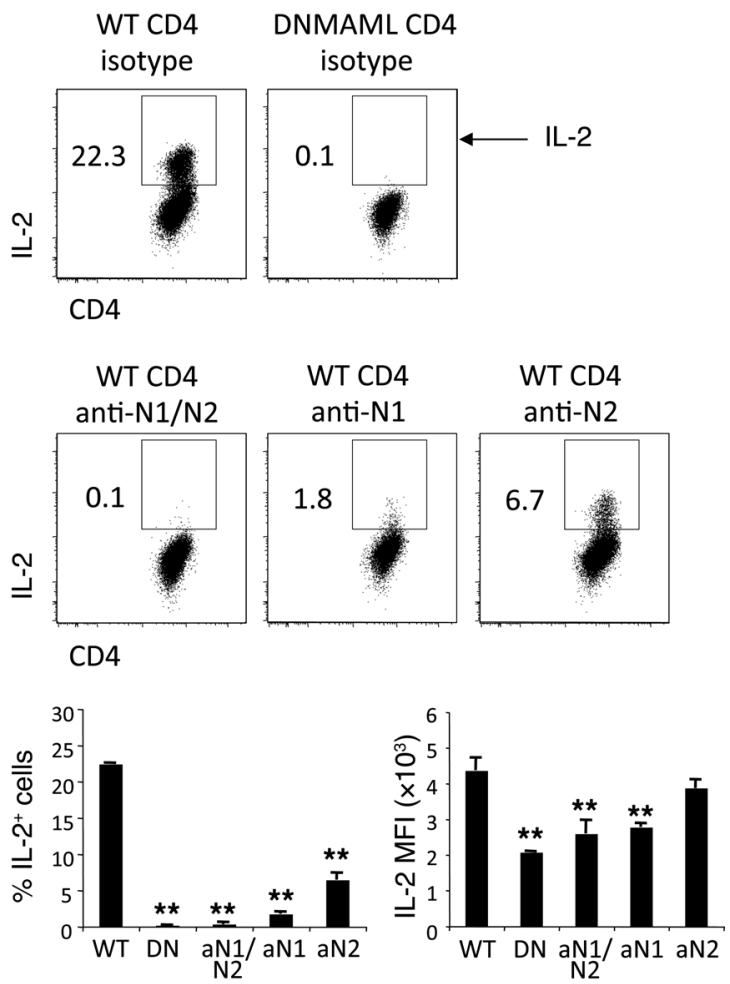

\section{Figure 2}

Notch1 and Notch2 control the production of IFN- $\gamma$ and IL-2 by alloreactive T cells, with dominant effects of Notch1. WT or DNMAML B6 T cells were transplanted into irradiated BALB/c recipients (9 Gy). Isotype control, anti-Notch1 (anti-N1), anti-Notch2 (anti-N2), or both anti-Notch1/ Notch2 antibodies were administered at day 0 and day 3. DNMAML T cells exposed to isotype control antibodies were a positive control for panNotch inhibition. (A) Intracellular staining for IFN- $\gamma$ in donor-derived $\mathrm{H} 2 \mathrm{~Kb}+\mathrm{H} 2 \mathrm{Kd}^{-} \mathrm{CD} 4{ }^{+}$spleen $\mathrm{T}$ cells after anti-CD3/CD28 restimulation. MFI of the IFN- $\gamma^{+}$cells is shown. (B) Intracellular staining for IL-2 under the same conditions. MFI of IL-2+ cells is shown. Representative flow cytometry plots are shown. Numbers indicate the percentage of cells in each quadrant. Bar graphs represent mean $\pm \operatorname{SD}(n=3)$ from 1 of 3 representative experiments. ${ }^{\star \star} P<0.01$.

and Dll4. In particular, combined blockade of Dll1 and Dll4 was safely achieved after allo-BMT, with no evidence of intestinal side effects. Remarkably, transient Dll1 and Dll4 inhibition was sufficient to provide long-lasting protection against GVHD. Protection was associated with persistent Treg expansion. These findings identify strategies for safely and efficiently targeting individual elements of the Notch pathway after alloBMT, which could lead to new strategies for GVHD control in human patients. Since aberrant Notch signaling has been linked to many human diseases, our work may have broad implications beyond GVHD toward selective therapeutic targeting of individual Notch pathway components.

\section{Results}

Pharmacological pan-Notch inhibitors block Notch signaling in alloreactive $T$ cells but lead to severe gastrointestinal toxicity. The rate-limiting step in proteolytic activation of the Notch receptors can be targeted with GSIs, a class of compounds available for preclinical and early clinical interventions (26). To assess the potential of pan-Notch inhibition with GSIs to control GVHD, we used the C57BL/6 (B6) anti-BALB/c MHC-mismatched model of allo-BMT and treated recipient mice with the GSI dibenzaz- epine (DBZ). DBZ decreased the production of inflammatory cytokines such as IFN- $\gamma$ and IL-2 by alloreactive T cells to an extent similar to that of genetic blockade of Notch signaling by DNMAML (Figure 1, A and B, and ref. 9). DBZ-treated WT and vehicle-treated DNMAML T cells had similarly decreased expression of Dtx 1, a direct Notch target gene (Figure 1B), indicating efficient inhibition of Notch signaling. To assess whether DBZ-mediated pan-Notch inhibition resulted in improved outcome, we monitored survival of allo-BMT recipients (Figure 1C). While DNMAML-mediated Notch blockade in alloreactive $\mathrm{T}$ cells drastically reduced GVHD severity and increased survival of allo-BMT recipients (9), DBZ-treated mice died within 4-8 days after transplantation, with signs of severe diarrhea, even when no $\mathrm{T}$ cells were present in the donor inoculum (Figure 1C). Histological examination of the small intestine showed decreased villus height (Figure 1D) and markedly decreased BrdU incorporation (Figure 1E). This rapid lethality and intestinal toxicity were much more severe than previously reported with GSIs in steadystate conditions, suggesting an essential role for Notch signaling in supporting recovery of intestinal integrity after total body irradiation. Thus, GSIs can target Notch in alloreactive T cells, but lead to profound intestinal adverse effects after allo-BMT. 
A

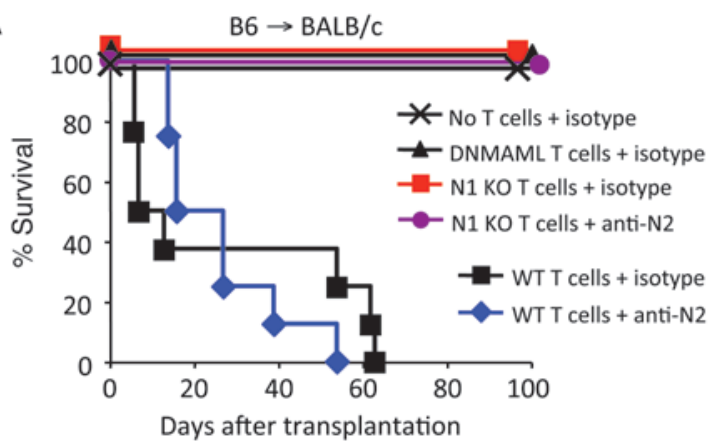

C

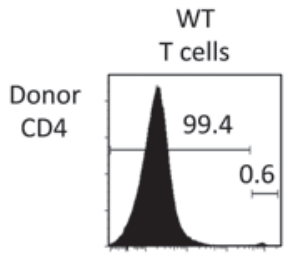

Donor CD8
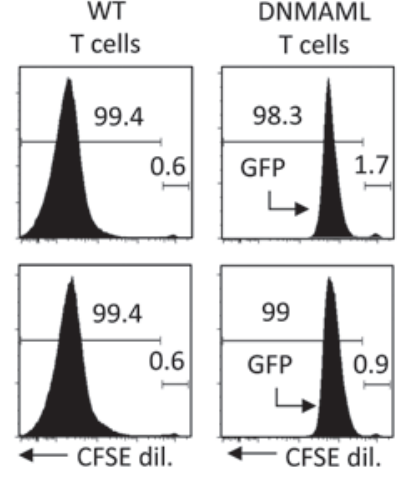

$\mathbf{E}$

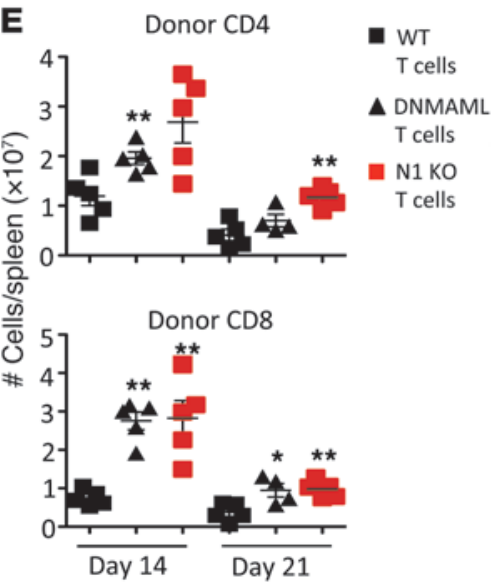

N1 KO
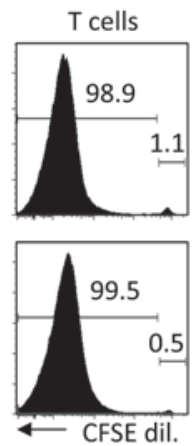

B
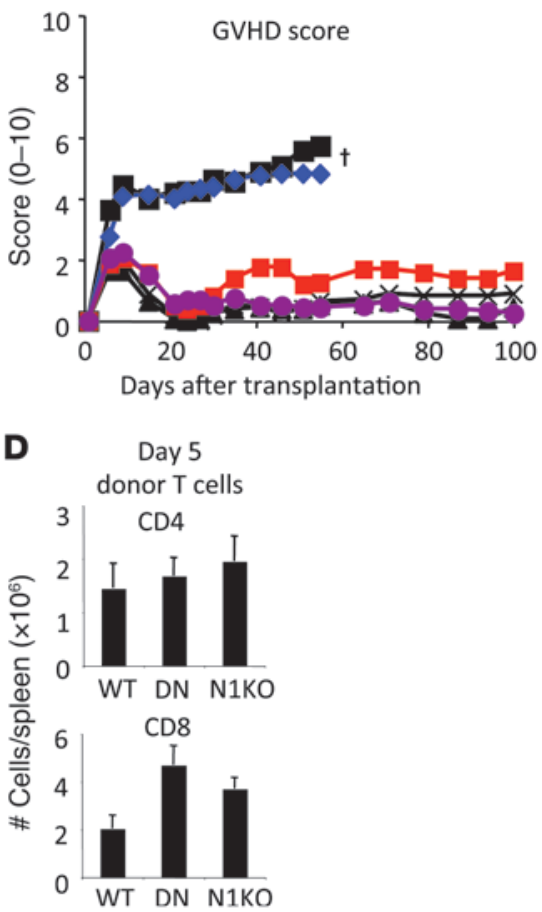

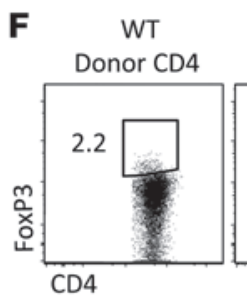

DNMAML N1 KO Donor CD4 Donor CD4
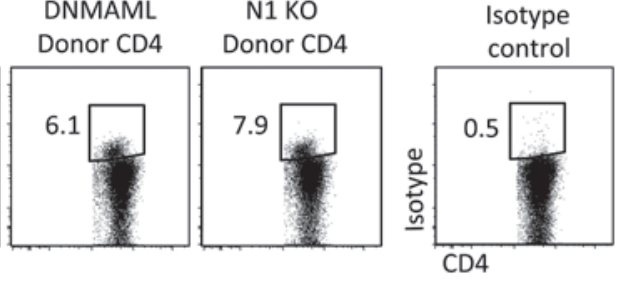

$\%$ FoxP3 ${ }^{+} \mathrm{CD}^{+} \mathrm{T}$ cells

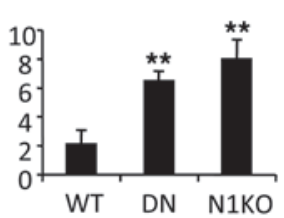

\# Donor FoxP3 ${ }^{+} \mathrm{T}$ cells d14 spleen $\left(x 10^{6}\right)$

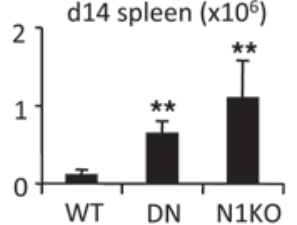

Figure 3

Notch1 inactivation in T cells is sufficient to protect mice from lethal GVHD. Irradiated BALB/c mice (9 Gy) were infused with TCD BM and WT, DNMAML, or Notch $1^{\text {flf }} \mathrm{Cd} 4-\mathrm{Cre}^{+}(\mathrm{N} 1 \mathrm{KO})$ spleen B6 T cells. Isotype control or anti-Notch2 antibodies $(5 \mathrm{mg} / \mathrm{kg})$ were administered i.p. twice weekly. (A) Survival after transplantation and (B) clinical GVHD score showing protection from lethal GVHD in groups transplanted with DNMAML or Notch1 KO T cells, irrespective of Notch2 blockade $(P<0.0001$ for TCD BM, DNMAML, Notch1 KO groups vs. WT isotype and WT anti-Notch2) ( $n=8$ /group). Cross indicates death of all mice by the indicated time point. Preserved in vivo proliferation (C) and expansion (D) of DNMAML and Notch1 KO CD4+ and CD8+ T cells. Donor-derived H2Kb+H2Kd-CFSE-labeled T cells were tracked in the spleen at day 5 after transplantation. DNMAML-GFP was present in the same channel as CFSE fluorescence. (E) Increased expansion of DNMAML and Notch1 KO T cells at days 14 and 21 after transplantation. Graphs show the number of donor-derived $\mathrm{H} 2 \mathrm{~Kb}^{+} \mathrm{H}_{2} \mathrm{Kd}^{-} \mathrm{CD} 4^{+}$or $\mathrm{CD}^{+} \mathrm{T}$ cells in the spleen. (F) Increased percentage and absolute numbers of donor FoxP $3^{+}$Tregs upon DNMAML expression or Notch1 inactivation. Representative flow cytometry plots are shown, including a sample stained with isotype control antibodies. Bar graphs represent mean $\pm \mathrm{SD}$. ${ }^{* \star} P<0.01 ;{ }^{*} P<0.05$.

Notch1 and Notch2 account for all the effects of Notch signaling in alloreactive $T$ cells, with a dominant role for Notch1. In steady-state conditions, Notch1 and Notch2 exert largely redundant functions in the gut epithelium $(24,27,28)$. Thus, targeting only Notch 1 or Notch 2 could be safer than pan-Notch inhibition after allo-BMT. We studied Notch1-4 expression in naive and alloreactive CD $4^{+}$ and $\mathrm{CD}^{+} \mathrm{T}$ cells (Supplemental Figure 1; supplemental material available online with this article; doi:10.1172/JCI65477DS1). Both Notch1 and Notch2 transcripts were present (Supplemental Figure 1A). Notch1 mRNA was more abundant than Notch2 mRNA. Notch3 and Notch4 transcripts were not detectable, even in activated alloreactive $\mathrm{T}$ cells (Supplemental Figure 1, B and C). To assess the 

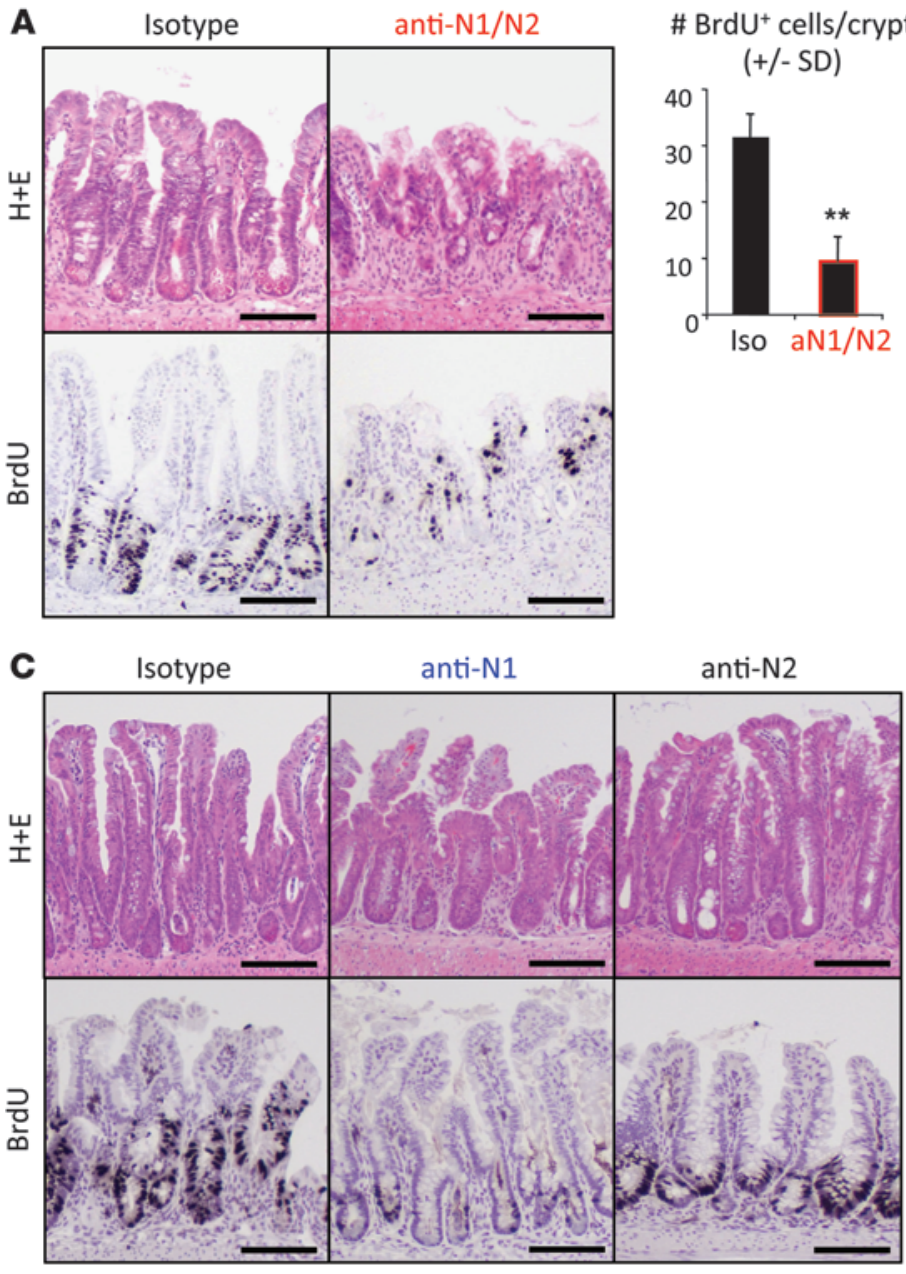
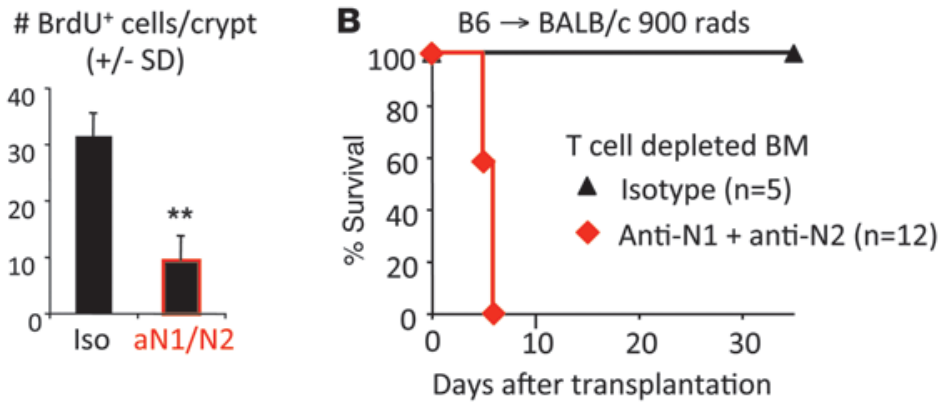

\section{Figure 4}

Dominant role of Notch1 in intestinal regeneration after BM transplantation. BALB/c mice were lethally irradiated (9 Gy) and transplanted with TCD B6 BM ( $5 \times 10^{6}$ cells). Monoclonal antibodies $(5 \mathrm{mg} / \mathrm{kg})$ were administered i.p. twice weekly. (A) H\&E staining and anti-BrdU immunohistochemistry of ileum in mice treated with isotype control or combined anti-Notch1/Notch2 antibodies (day 4). BrdU was given i.p. 2 hours before euthanasia. The number of BrdU + crypts was quantified in 6-10 crypts/mouse. Bar graphs represent mean $\pm \operatorname{SD}\left(n=3 /\right.$ group). ${ }^{\star \star} P<0.01$. (B) Rapid lethality in anti-Notch1/Notch2-treated mice, as seen with GSI treatment (Figure 1). Isotype control, $n=5$; anti-Notch1/Notch2, $n=12$. (C) H\&E and anti-BrdU staining of ileum in mice treated with isotype control (day 5), anti-Notch1 (day 6), or anti-Notch2 antibodies (day 5). Bar graphs represent mean \pm SD ( $n=3$ /group). Scale bars: $100 \mu \mathrm{m}$. (D) Rapid lethality in anti-Notch1-treated mice, consistent with the major effects of Notch1 blockade on intestinal regeneration as seen in C. This was not the case with anti-Notch2 alone (see Figure 3A). Isotype control, $n=5$; anti-Notch1, $n=6$ mice/group.

respective roles of Notch1 and Notch2 functionally, we used humanized antibodies that target the extracellular negative regulatory region of each receptor to prevent Notch activation (24). As a control for the quality of these reagents, we found that in vivo administration of anti-Notch 1 or anti-Notch2 antibodies led to profound depletion of Notch1-dependent thymocytes and Notch2-dependent marginal zone B (MZB) cells, respectively, with no crossreactivity (Supplemental Figure 2 and refs. 12, 29). These findings indicate high efficacy and specificity.

We tested the impact of Notch1 and/or Notch2 inhibition after allo-BMT, using cytokine production as surrogate end point and DNMAML $\mathrm{T}$ cells as positive control for efficient pan-Notch inhibition (Figure 2). Combined Notch1 and Notch2 blockade reduced IFN- $\gamma$ (Figure $2 \mathrm{~A}$ ) and IL-2 (Figure $2 \mathrm{~B}$ ) production by alloreactive $\mathrm{T}$ cells to an extent similar to that of DNMAML expression. Notch1 inhibition alone was sufficient to partially block IFN- $\gamma$ and prevent IL-2 production. Notch2 blockade had minor effects on the MFI of IFN- $\gamma$ staining and on IL-2 production. This indicated a dominant role for Notch1, with additional contribution from Notch2. To verify that Notch receptors exert cell-autonomous effects in T cells, we studied alloreactive T cells with genetic inactivation of Notch1, Notch2 (Supplemental Figure 3 ), or both (Supplemental Figure 4). Production of IFN- $\gamma$ and IL-2 in $\mathrm{CD}^{+} \mathrm{T}$ cells and IFN- $\gamma$ in $\mathrm{CD}^{+} \mathrm{T}$ cells was profoundly decreased upon DNMAML expression or combined Notch $1 / 2$ inhibition (Notch1 inactivation with systemic Notch2 blockade, Notch2 inactivation with systemic Notch1 blockade, or Notch1/ Notch2 inactivation). Thus, cell-autonomous effects of Notch1 and Notch2 accounted for all the effects of Notch signaling in alloreactive $\mathrm{CD}^{+}$and $\mathrm{CD}^{+} \mathrm{T}$ cells, with a dominant role for Notch1. 


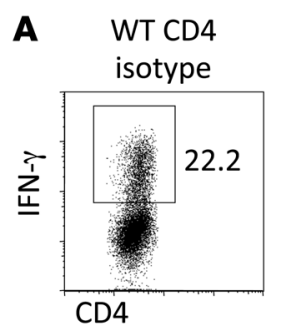

WT CD4 anti-DII/DII4
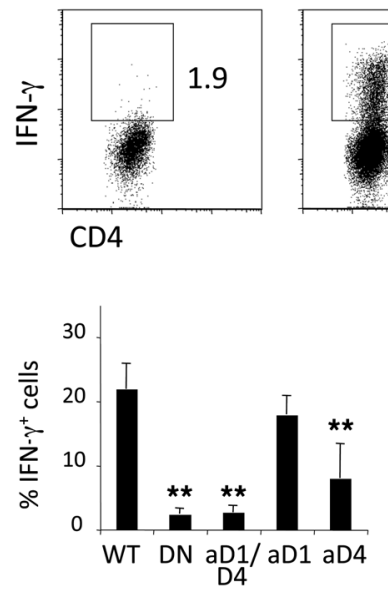

DNMAML CD4 isotype

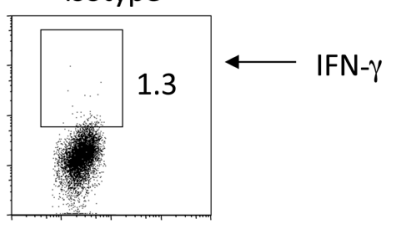

WT CD4 anti-DII1

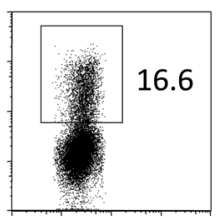

WT CD4 anti-Dll4
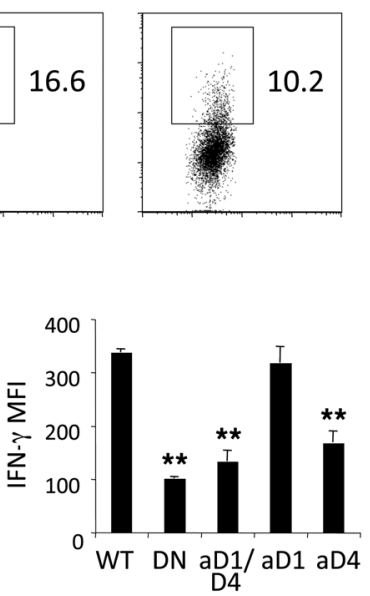

B WT CD4 isotype

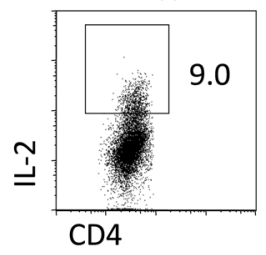

WT CD4 anti-DII1/DII4
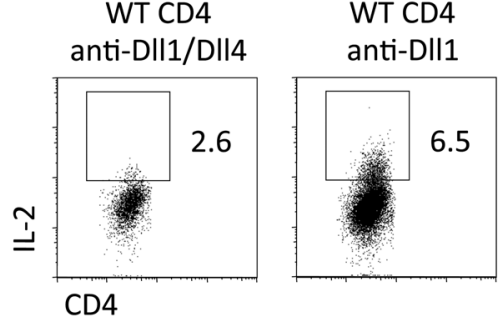

WT CD4 anti-DII4

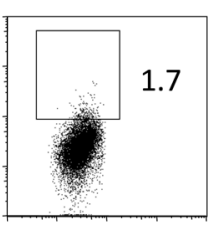

DNMAML CD4 isotype

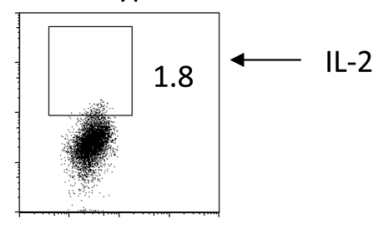

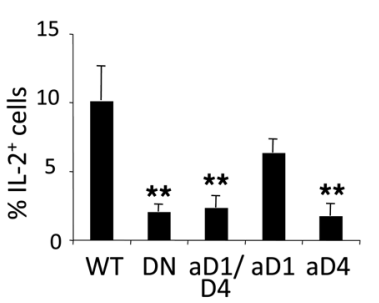

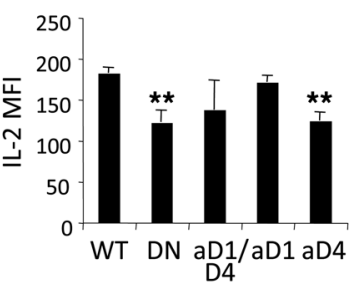

\section{Figure 5}

DII1 and DII4 Notch ligands control the production of IFN- $\gamma$ and IL-2 by alloreactive T cells, with dominant effects of DII4. WT or DNMAML B6 T cells were transplanted into irradiated BALB/c recipients (9 Gy). Isotype control, anti-DIl1, anti-DII4, or anti-D\|l1/DII4 antibodies were administered at day 0 and day 3. DNMAML T cells exposed to isotype control antibodies were a positive control for pan-Notch inhibition. (A) Intracellular staining for IFN- $\gamma$ in donor-derived $\mathrm{H} 2 \mathrm{~Kb}^{+} \mathrm{H} 2 \mathrm{Kd}^{-} \mathrm{CD} 4^{+}$spleen T cells after anti-CD3/CD28 restimulation. MFI of IFN- $\gamma^{+}$cells is shown. (B) Intracellular staining for IL-2 under the same conditions. MFI of IL-2+ cells is shown. Representative flow cytometry plots are shown. Numbers indicate the percentage of cells in each quadrant. Bar graphs represent mean $\pm \operatorname{SD}(n=3)$ from 1 of 3 representative experiments. ${ }^{\star \star} P<0.01$.

Notch1 inactivation in donor T cells protects mice from acute GVHD. In view of Notch1's dominant effects on cytokine production, we assessed the impact of Notch1 inactivation in T cells on GVHD severity and mortality (Figure $3, \mathrm{~A}$ and $\mathrm{B}$ ). BALB/c recipients of Notch1-deficient B6 T cells survived as well as mice receiving B6 DNMAML T cells or T cell-depleted (TCD) BM only, regardless of systemic Notch2 blockade. Moreover, Notch2 inhibition alone did not decrease GVHD mortality and severity.

To understand the basis for the dominant effects of Notch1, we compared Notch1-deficient and DNMAML alloreactive T cells (Figure 3, C-F). DNMAML expression or Notch1 inactivation did not impair in vivo proliferation and expansion of donor-derived $\mathrm{CD}^{+}{ }^{+}$and $\mathrm{CD}^{+}{ }^{+} \mathrm{T}$ cells (Figure 3, C and D). This was consistent with the absence of global immunosuppression. At later time points after allo-BMT, both DNMAML and Notch1-deficient $\mathrm{T}$ cells showed enhanced expansion in the spleen (Figure $3 \mathrm{E}$ ) and other lymphohematopoietic organs (not shown). Because proliferation was not changed, this was likely due to decreased $\mathrm{T}$ cell death in the absence of Notch signaling. In addition, both DNMAML and Notch1-deficient $T$ cells led to increased accumulation of FoxP3 ${ }^{+}$Tregs (Figure 3F). Thus, pan-Notch inhibition with DNMAML and isolated Notch1 inactivation had similar effects on alloreactive T cells (Figures 2 and 3), identifying Notch 1 in T cells as a possible therapeutic target in GVHD.
Systemic Notch1 blockade leads to severe gastrointestinal toxicity after BM transplantation. To assess whether Notch1 could be inhibited safely after allo-BMT, we studied intestinal homeostasis and survival in allo-BMT recipients treated with anti-Notch1 or antiNotch1/Notch2 antibodies. Histological analysis showed markedly reduced proliferation and disrupted epithelial integrity with anti-Notch1/Notch2 treatment, as seen with DBZ (Figure 4A and Figure 1). Consistently, combined Notch1 and Notch2 inhibition led to rapid lethality (Figure 4B). Intestinal toxicity with antiNotch 1 treatment was also severe, although somewhat delayed, with reduced proliferation seen 2 days later than with combined receptor blockade, while Notch2 blockade alone had minimal effects (Figure 4C). Overall survival of anti-Notch1-treated mice was very short (Figure 4D). These findings differ from the mild effects of Notch1 inhibition alone in the gut during steady-state conditions (24), indicating an increased dependence on Notch1mediated signals during intestinal regeneration after allo-BMT. Interestingly, Notch blockade after irradiation did not induce goblet cell hyperplasia, a hallmark of Notch inhibition during steady-state conditions (Supplemental Figure 5 and ref. 28). This observation suggests an effect of Notch 1 on primitive intestinal progenitors required for intestinal recovery. Thus, although Notch 1 is an attractive target, its systemic inhibition cannot be achieved safely after allo-BMT. 

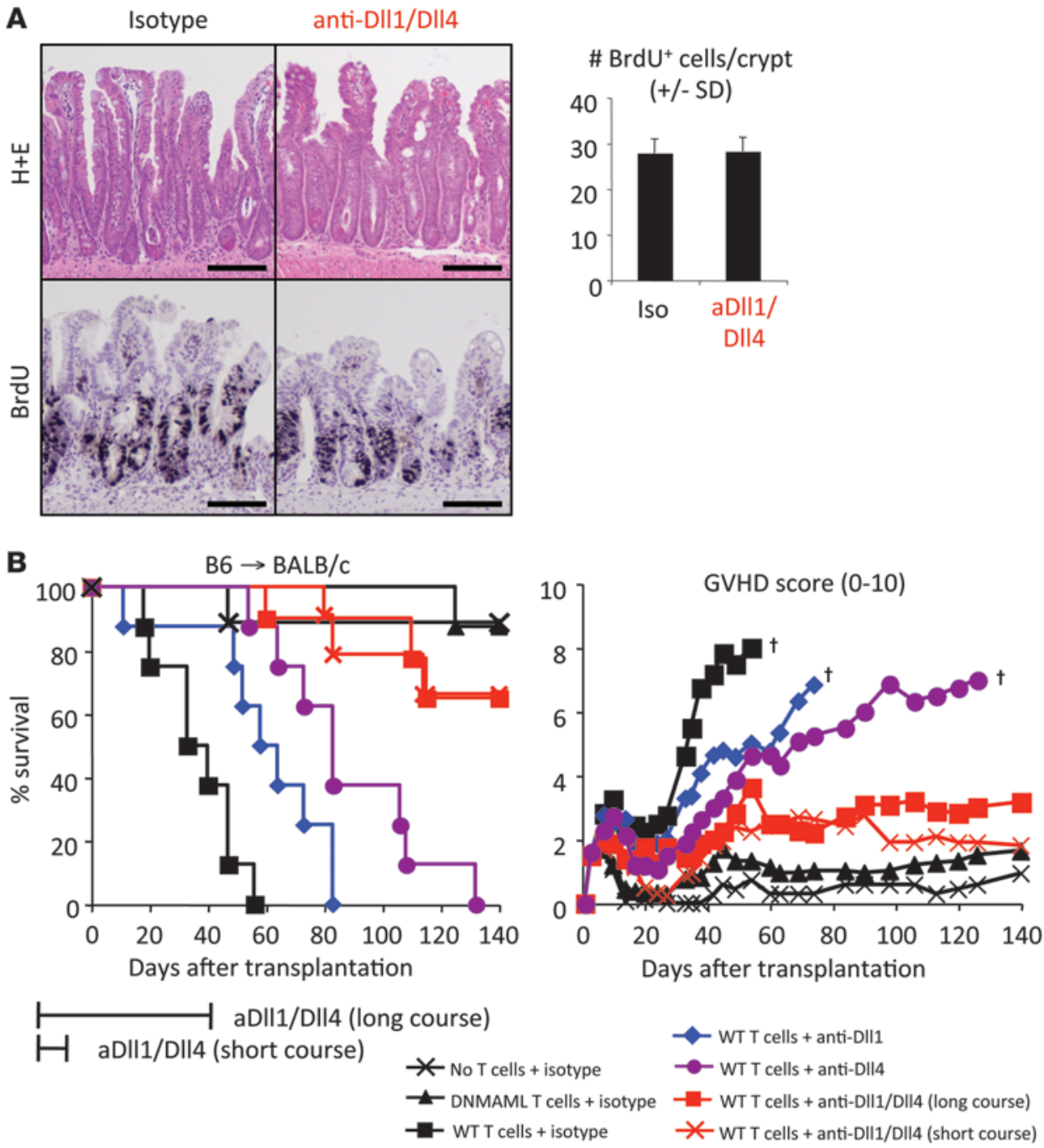

C

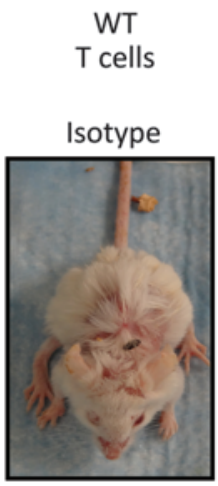

No
T cells

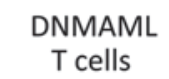

T cells

Isotype

Isotype

aDII1/D\|4
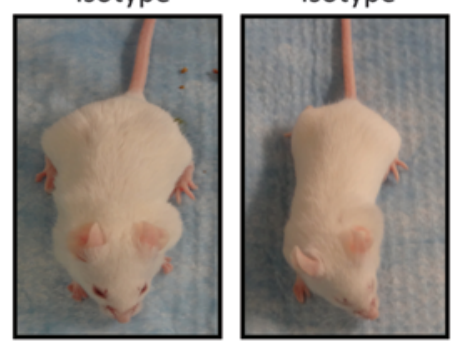

short course
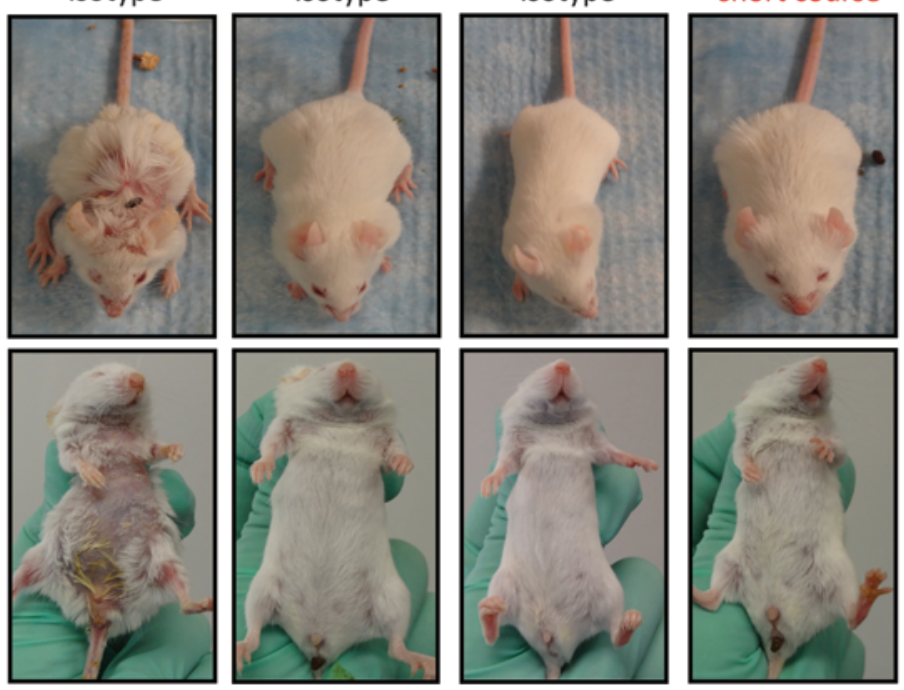

Figure 6

Transient blockade of DII1 and DII4 protects mice from lethal GVHD without inducing intestinal toxicity. (A) BALB/c mice were lethally irradiated (9 Gy) and transplanted with TCD B6 BM $\left(5 \times 10^{6}\right.$ cells). Anti-DIl1 and anti-DIIL4 antibodies ( $\left.5 \mathrm{mg} / \mathrm{kg}\right)$ were administered i.p. on day 0 and day 3. Preserved intestinal architecture and BrdU incorporation (H\&E and anti-BrdU staining, day 5) indicating absence of intestinal toxicity. (B and $\mathbf{C}$ ) Irradiated BALB/c mice (9 Gy) were infused with TCD B6 BM, with or without WT or DNMAML spleen B6 T cells. Isotype control, antiDII1, anti-DII4, or anti-DII1/DII4 antibodies were administered twice weekly for 60 days (long course) or 10 days (short course: days $0,3,7$, and 10). Scale bars: $100 \mu \mathrm{m}$. (B) Survival after transplantation and clinical GVHD score demonstrate increasing protection with DII1, DII4, and combined DII1/DII4 blockade $(P=0.005$, WT vs. anti-D\|l $1 ; P=0.0001$, WT vs. anti-D\|l4; $P<0.0001$, WT vs. anti-DII1/D\|4). Anti-DII1/DII4 antibodies provided nearly as much protection as DNMAML T cells, even upon short-term administration ( $P=0.21$, DNMAML vs. anti-D\|l1/D\|4 groups) ( $n=8 /$ group). Crosses indicate death of all mice by the indicated time point. (C) Representative photographs illustrating protection from GVHD (see also Supplemental Figure 7). 
A

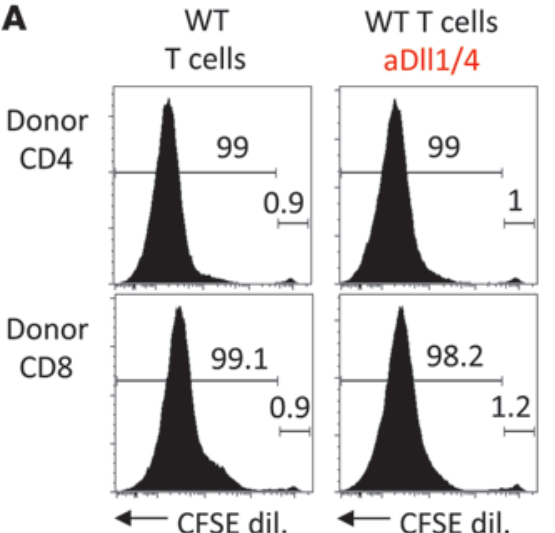

B WT $T$ cells

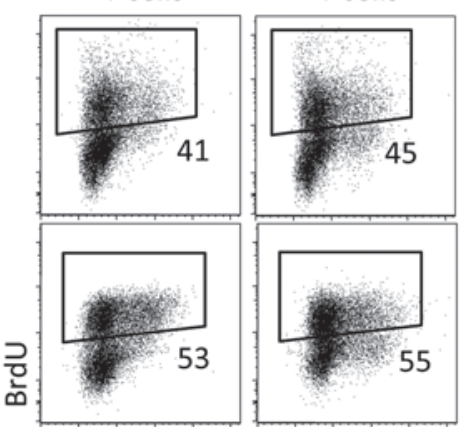

DAPI (DNA content)
$\% \mathrm{BrdU}^{+}$

donor T cells

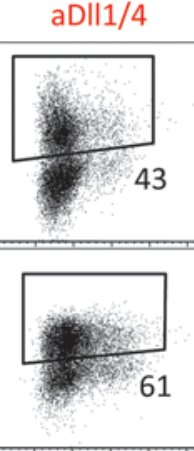

1
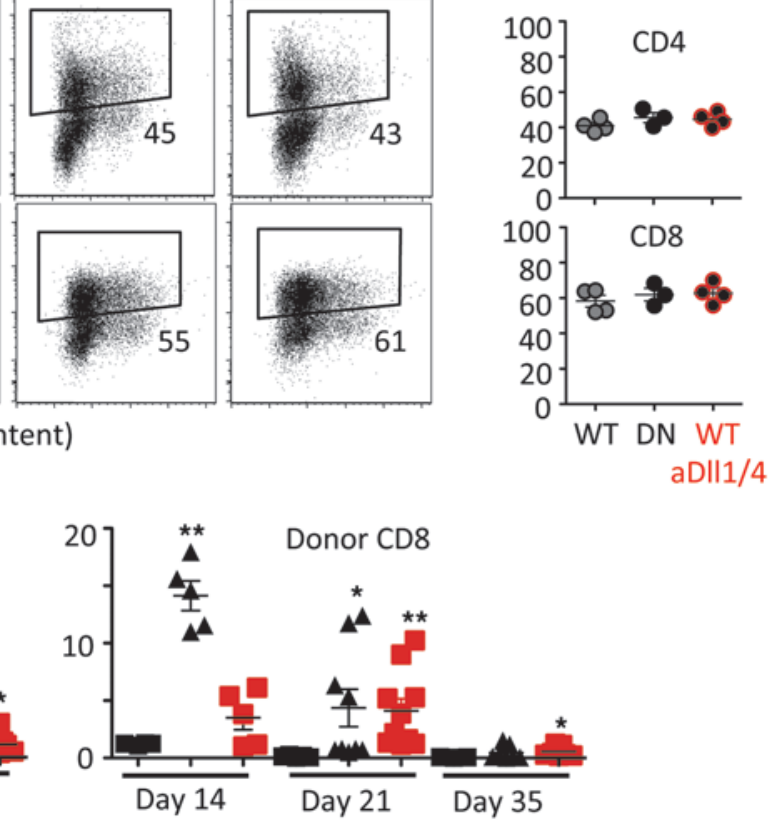

D

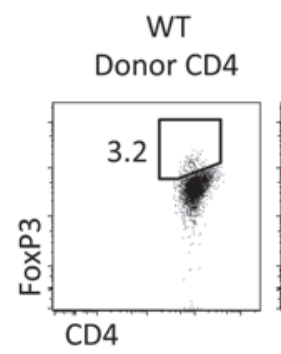

Day 35 spleen

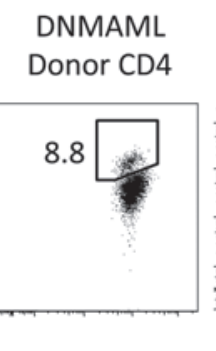

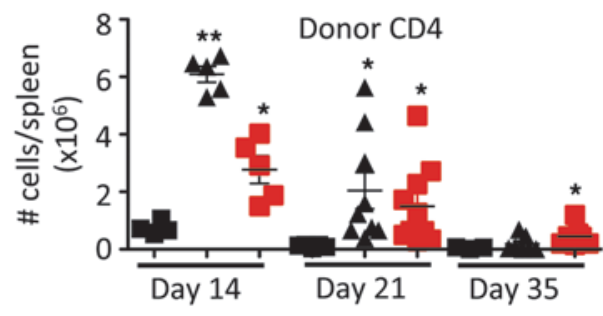

C

\section{DNMAML \\ $T$ cells \\ WT T cells aDII1/4}

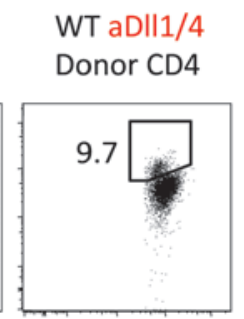

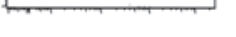

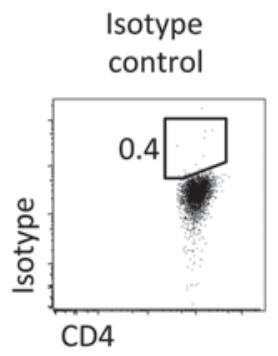

Isotype

Figure 7

Preserved in vivo T cell proliferation and increased expansion of Tregs upon transient DII1/DIl4 blockade. Irradiated BALB/c mice (9 Gy) were infused with TCD BM, with or without WT or DNMAML spleen T cells. Isotype control or anti-DII1/DIIL4 antibodies were administered transiently (days $0,3,7$, and 10). (A) Preserved in vivo proliferation as assessed by tracking CFSE-labeled donor-derived T cells and (B) BrdU incorporation on day 5 after allo-BMT. (C) Expansion of WT, DNMAML, and WT T cells in anti-Dll1/DII4-treated mice at days 14, 21, and 35 after transplantation. Graphs show the absolute number of donor-derived $\mathrm{H}_{2} \mathrm{~Kb}^{+} \mathrm{H} 2 \mathrm{Kd}^{-} \mathrm{CD} 4^{+}$or $\mathrm{CD}^{+} \mathrm{T}$ cells in the spleen of individual recipients. (D) Short-term DII1/DII4 inhibition was associated with persistently elevated percentages and absolute number of Tregs at day 35 . Representative flow cytometry plots for intracellular FoxP3 staining are shown, including a sample stained with isotype control antibodies. Numbers indicate the percentage of cells in each quadrant. Bar graphs represent mean $\pm \mathrm{SD} .{ }^{* \star} P<0.01 ;{ }^{*} P<0.05$.

Dll1 and Dll4 Notch ligands mediate Notch signaling in alloreactive $T$ cells, with a dominant role for Dll4. Past reports suggested a role for Delta-like and not Jagged ligands in promoting Th1-like inflammatory $\mathrm{T}$ cell responses, which dominate in GVHD (30). Thus, we studied the possibility of inhibiting Dll1 and Dll4, the 2 agonistic Delta-like ligands, using newly developed neutralizing antibodies that target the Dll1 or Dll4 extracellular domain $(10,31)$. As a control, these antibodies led to profound depletion of Dll1-dependent MZB cells and Dll4-dependent thymocytes, respectively, showing high efficiency and specificity (Supplemental Figure 6 and refs. 32, 33). After allo-BMT, combined inhibition of Dll1 and Dll4 blocked production of IFN- $\gamma$ and IL- 2 to an extent similar to that of DNMAML expression in T cells (Figure
5). Anti-Dll4 antibodies had the most profound effects, while Dll1 blockade only had a minimal impact by itself. Together, compared with the effects of DNMAML-mediated pan-Notch inhibition, Dll1 and Dll4 appeared to account for all the effects of Notch signaling on cytokine secretion by alloreactive T cells, with a dominant role for Dll4.

Dll1 and Dll4 blockade abrogates acute GVHD, even when applied transiently after BM transplantation. To evaluate the safety of Dll1/ Dll4 blockade, we studied intestinal recovery after allo-BMT. Unlike DBZ or anti-Notch1 antibodies, anti-Dll1/Dll4 treatment had no detectable effect on morphology and BrdU incorporation in the small intestine (Figure 6A). Thus, we assessed whether Dll1 and/or Dll4 blockade could protect mice from the 

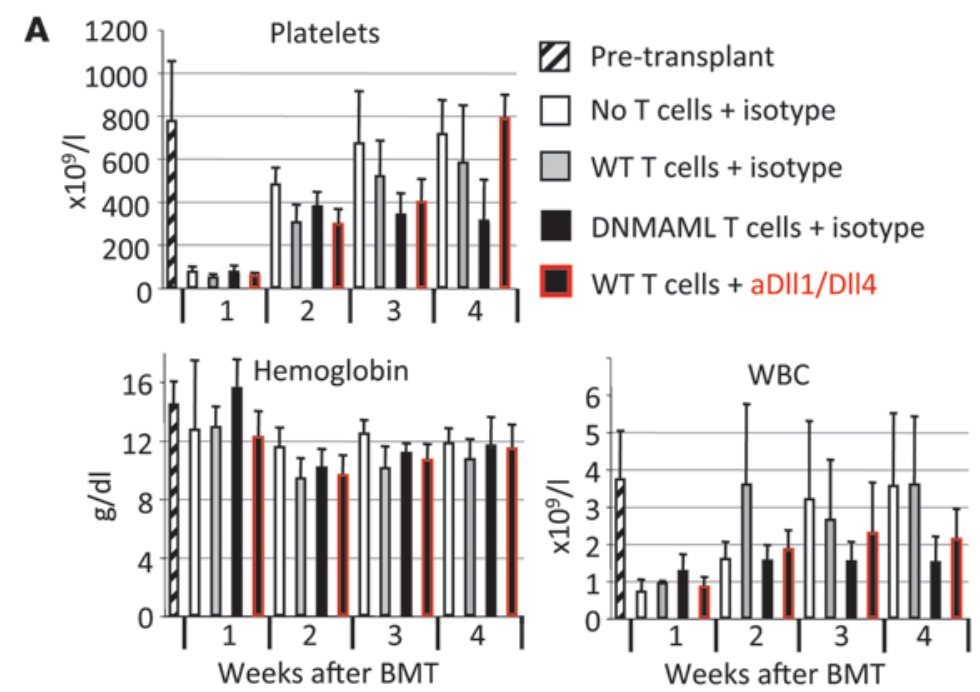

C

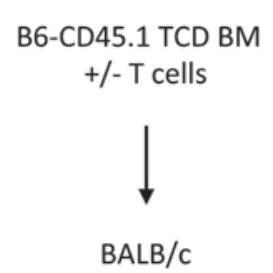

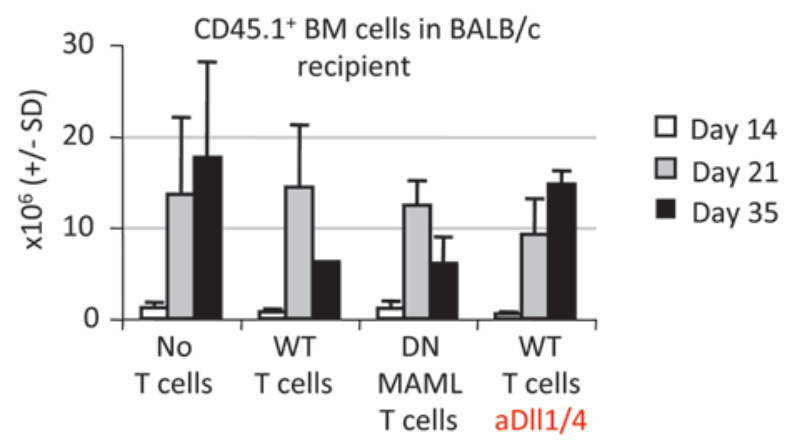

B

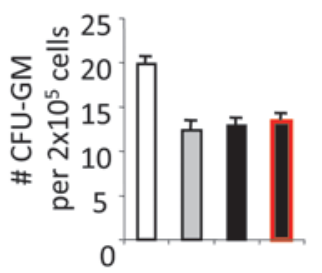

Day 21 BM CFU

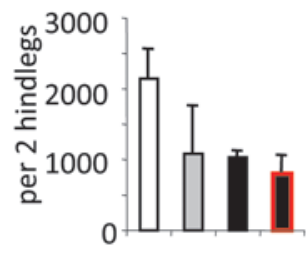

No T cells + isotype

WT T cells + isotype

DNMAML T cells + isotype

WT T cells + aDII1/DII4

\section{Figure 8}

Preserved hematopoietic recovery after allogeneic transplantation in mice treated with anti-DII1/DII4 antibodies. Allo-BMT and transient administration of anti-DII1/DII4 or control antibodies (days 0-10) were performed as described in Figure 6. (A) Weekly complete blood counts after alloBMT showing unimpaired recovery in recipients treated with anti-DII1/DII4 antibodies. (B) CFU-GM activity in the BM on day 21 after transplantation. (C) Absolute numbers of CD45.1+ cells derived from B6-CD45.1 donor TCD BM at days 14, 21, and 35. This showed preserved engraftment and expansion of CD45.1+ donor-derived cells in the BM. Bar graphs represent mean \pm SD.

morbidity and lethality of acute GVHD (Figure 6B). Individual Dll1 or Dll4 inhibition extended the median survival of alloBMT recipients by approximately 25 and 50 days, respectively, although ultimately all animals succumbed to GVHD. However, when both Dll1 and Dll4 were inhibited, we observed increased long-term survival and decreased GVHD severity to an extent similar to that seen with DNMAML-mediated pan-Notch inhibition. Remarkably, short-term D1l1/Dll4 blockade after alloBMT (days 0-10) conferred as much protection as continuous blockade for 60 days after transplantation. Representative examples documenting the magnitude of the clinical protection are shown in Figure 6C and Supplemental Figure 7. Thus, targeting Delta-like ligands rather than Notch receptors did not induce limiting toxicity and revealed the protective effects of Notch inhibition in GVHD.

Dll1/Dll4 blockade does not impair T cell proliferation and induces persistent expansion of Tregs. We next investigated the impact of Dll1/ Dll4 inhibition on donor-derived alloreactive T cells. CFSE dilution (Figure 7A) and BrdU incorporation (Figure 7B) showed that Dll1/Dll4 blockade did not decrease proliferation of donor-derived $\mathrm{T}$ cells in vivo. At later time points, anti-Dll1/Dll4 treatment was associated with increased expansion of donor T cells in the spleen (Figure 7C) and other lymphohematopoietic organs (not shown). This was similar to our observations upon DNMAML expression or Notch1 loss (Figure 3), although increased expansion was less pronounced at day 14 in antibody-treated mice. Importantly, Dll1/ Dll4 blockade allowed for increased numbers of Tregs to accumulate at day 14 (data not shown), and this was maintained even after blocking antibodies had been cleared from recipient mice (Figure 7D, day 35). In selected experiments, Treg accumulation was documented with the use of Foxp3-IRES-mRFP ${ }^{+}$donor B6 T cells (Supplemental Figure 8 and ref. 34). Together, transient Dll1/ Dll4 inhibition blocked production of inflammatory cytokines (Figure 5) and led to a long-term increase in donor Tregs. To determine whether the expanding Treg population was sufficient to confer protection from GVHD, we cotransferred fresh B6 T cells with splenocytes recovered from primary transplant recipients exposed to control or anti-Dll1/Dll4 antibodies containing increased FoxP3 ${ }^{+} \mathrm{T}$ cells (Supplemental Figure 9). This strategy failed to protect the majority of secondary recipient mice, suggesting that Notch-deprived Tregs were not sufficient to block GVHD induced by Notch-competent T cells. 
A

A
No T cells
Isotype control
WT T cells
Isotype control
DNMAML T cells
Isotype control

Day 21

Thymus
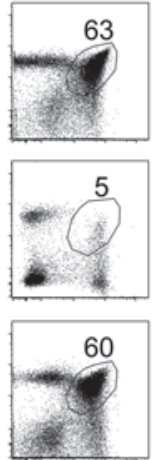

WT T cells

aDII1/4

Short course

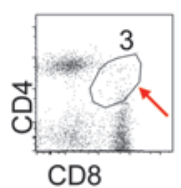

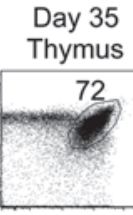

2.7
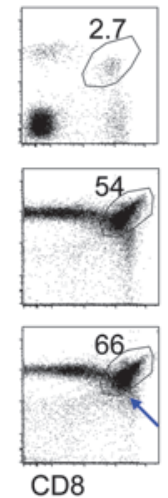

B

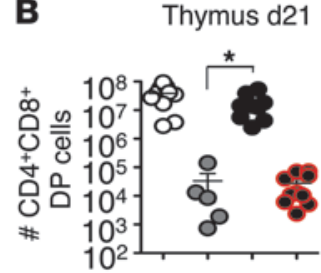

Thymus d35

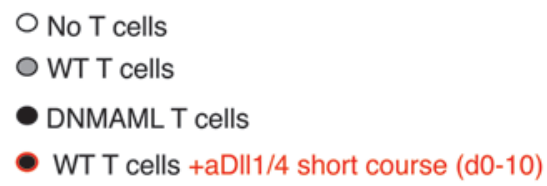

O No T cells

WT T cells

- WT T cells $+\mathrm{aDll} 1 / 4$ short course (d0-10)

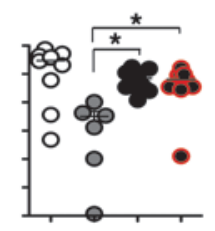

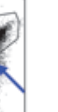

Figure 9

Protection from thymic GVHD upon transient systemic DIl1/DIl4 blockade. Lethally irradiated (8.5 Gy) BALB/c mice were transplanted with TCD BM $\left(5 \times 10^{6}\right.$ cells $)$ with or without WT or DNMAML T cells $\left(10 \times 10^{6}\right.$ splenocytes $)$. Isotype control vs. anti-DIl1/DII4 antibodies were administered i.p. at days $0,3,7$, and 10 (short course). (A) Thymus was assessed using flow cytometry to identify newly formed CD4 ${ }^{+} \mathrm{CD} 8^{+} \mathrm{DP}$ thymocytes. At day 21, thymopoiesis was inhibited in the presence of anti-DII4 antibodies (red arrow). At day 35, after antibody clearance, large numbers of DP thymocytes arose in anti-DII1/DII4-treated mice (blue arrow), indicating protection from GVHD-induced thymic damage. (B) Absolute number of CD4+CD8+ DP thymocytes at days 21 and 35 in individual allo-BMT recipients, quantifying preserved thymic recovery at day 35 in anti-DIl1/ DIl4-treated mice. ${ }^{*} P<0.05$.

Dll1 and Dll4 inhibition does not impair hematopoietic recovery after allo-BMT. To further assess the safety of short-term Dll1/D114 blockade, we studied hematopoietic and thymic reconstitution. Blood counts and in particular platelet recovery were not impaired by Dll1/Dll4 blockade (Figure $8 \mathrm{~A}$ ). BM progenitor contents were not affected as compared with mice receiving WT or DNMAML $\mathrm{T}$ cells (Figure 8B). When CD45.1 was used to track cells derived from the TCD BM, similar engraftment efficiency was observed (Figure 8C). Thus, no major defect in hematopoietic reconstitution was apparent in these conditions.

Thymic output after allo-BMT can be profoundly decreased by GVHD-induced damage to the thymic epithelium (tGVHD) $(35,36)$. However, Dll4 is the physiological ligand driving early $\mathrm{T}$ cell development in the thymus (32). We quantified $\mathrm{CD} 4^{+} \mathrm{CD} 8^{+}$ double-positive (DP) thymocytes as a measure of thymic function after allo-BMT (Figure 9). Recipients of WT T cells had markedly reduced DP numbers as a result of severe tGVHD. Infusion of DNMAML T cells preserved thymic cellularity, consistent with markedly decreased tGVHD. Interestingly, Dll1/Dll4 blockade was associated with low DP contents at day 21, consistent with blockade of Dll4-dependent T cell development. However, after time had elapsed allowing antibodies to be cleared, thymic cellularity increased up to levels seen in DNMAML recipients (day 35). Thus, transient Dll1/Dll4 inhibition protected the thymus from tGVHD, allowing good subsequent immune recovery.

Dll1/Dll4 blockade preserves substantial cytotoxicity and GVT activity. DNMAML expression and anti-Dll1/Dll4 antibodies blocked cytokine production without preventing $\mathrm{T}$ cell proliferation and expansion (Figures 5 and 6 ). We previously reported that DNMAML $\mathrm{T}$ cells have preserved cytotoxic activity and GVT potential (9). We next assessed the effect of short-term anti-Dll1/Dll4 treatment (Fig- ure 10). Overall cytotoxic potential was captured with an in vivo cytotoxicity assay (Figure 10, A and B). Allo-BMT recipients were challenged at day 14 with CFSE-labeled allogeneic target cells. Efficient elimination of allogeneic targets was observed in recipients of WT T cells treated with isotype control or anti-Dll1/Dll4 antibodies. Cytotoxic activity was slightly reduced in anti-Dll1/Dll4-treated recipients. However, it was efficient when compared with recipients of TCD BM only (Figure 10B). We next assessed whether the mice could control a challenge with host-type luciferase-expressing A20 tumor cells $\left(10^{6}\right.$ A20 cells/recipient; Figure 10, C and D). We chose to infuse A20 cells at the time of transplant so that the tumor cell dose could be precisely controlled. In the absence of donor $\mathrm{T}$ cells, rapid tumor progression was observed in all mice surviving beyond 3 weeks. WT T cells could control the leukemia, but induced lethal GVHD. Dll1/Dll4 blockade preserved tumor clearance in all allo-BMT recipients at this tumor cell dose (Figure 10, C and D). The magnitude of the GVT effects was further assessed with higher doses of tumor cells. As shown in Figure $10 \mathrm{E}$, we observed a fraction of anti-Dll1/Dll4-treated mice with late tumor relapse when the tumor cell dose was raised 5-fold. These data show that Notch blockade with anti-Dll1/Dll4 antibodies blocked GVHD while preserving substantial GVT activity.

Next, we determined whether Dll1/Dll4 blockade impaired NK cell-mediated cytotoxic functions, as alloresponsive NK cells can play an important role in human transplant recipients, especially in the presence of MHC mismatches (37-41). Past work in classical "hybrid resistance" models has shown that NK cells from hybrid F1 mice exert cytotoxicity against parental hematopoietic cells in the absence of T cell-mediated effects, as F1 T cells are tolerant to parental alloantigens (42-45). B6 $\times \mathrm{BALB} / \mathrm{c}$ were treated with isotype control or anti-Dll1/Dll4 antibodies followed by poly(I:C) to enhance NK cell function $(46,47)$. We challenged these mice with CFSE- 
A

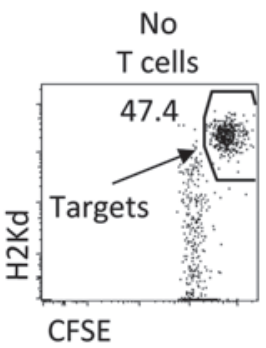

c
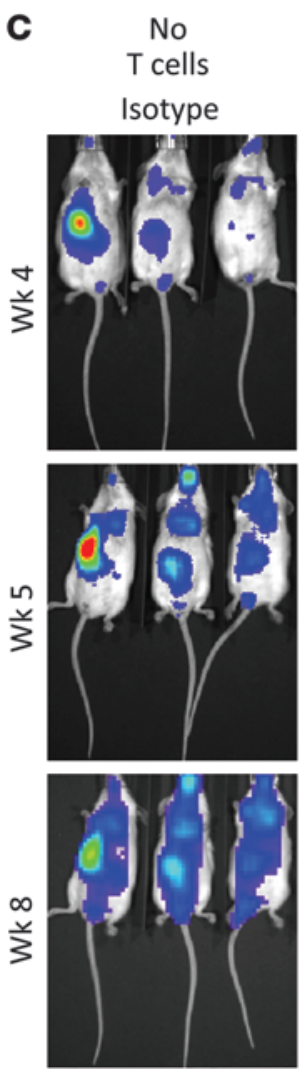
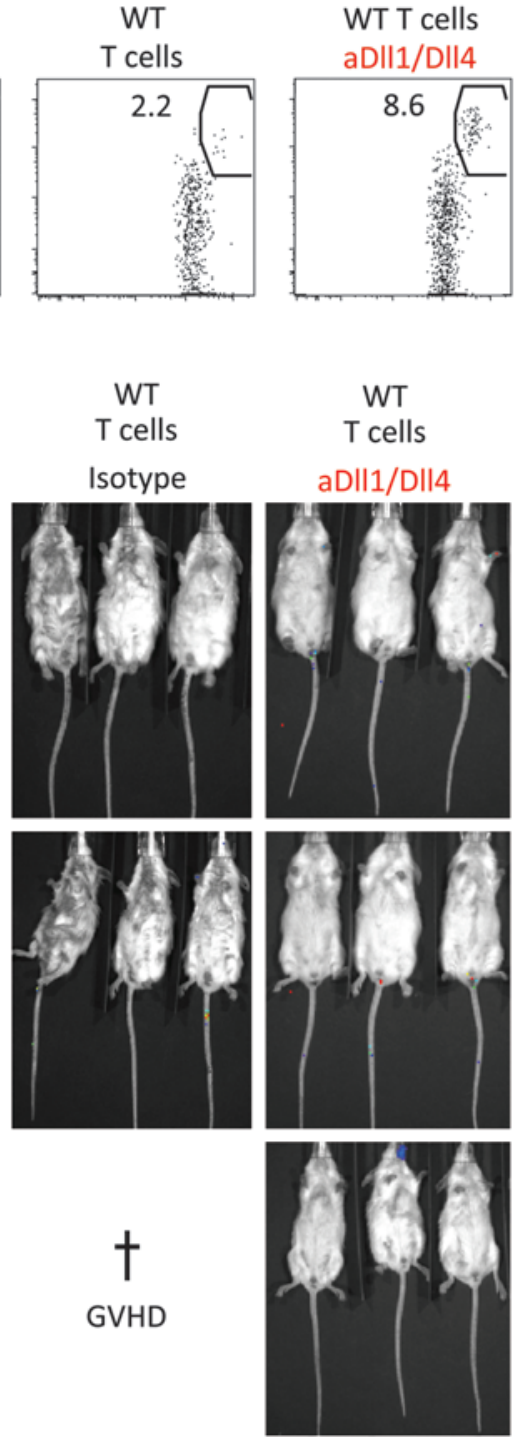

B

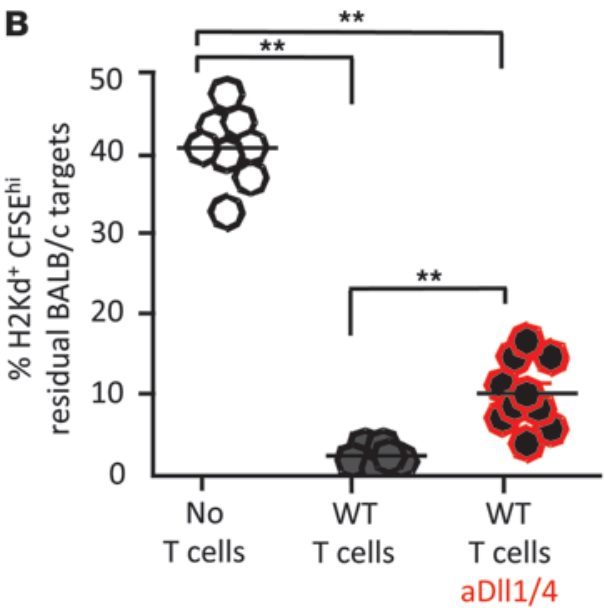

D

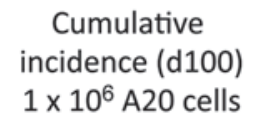

$\mathbf{E}$

Cumulative incidence (d70) $5 \times 10^{6}$ A20 cells

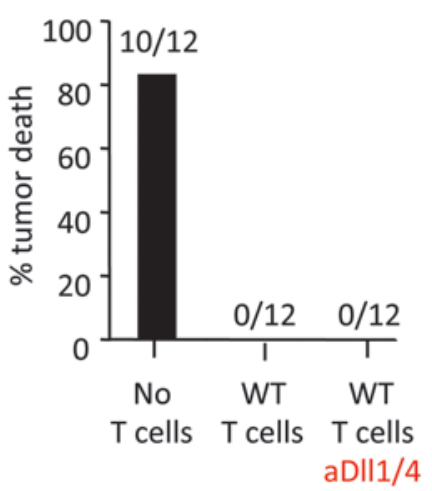

Figure 10

DII1/DII4 blockade preserves substantial in vivo cytotoxicity and GVT effects. Allo-BMT and transient administration of anti-DII1/DII4 or control antibodies (days $0-10$ ) were performed as described in Figure 6 legend. (A) In vivo cytotoxicity assay. Allo-BMT recipient mice were challenged on day 14 with a 1:1 infusion of CFSE-labeled allogeneic targets and control cells (CFSE splenocytes, respectively). After 18 hours, elimination of the BALB/c targets was assessed in the spleen by flow cytometry. (B) Summary of in vivo cytotoxicity data in individual mice $\left(n=6-10 /\right.$ group). ${ }^{* \star} P<0.01$. (C) Bioluminescence imaging was performed at the indicated time points after allo-BMT and infusion of host-type $\left(\mathrm{H}-2 \mathrm{Kd}^{+}\right)$A20-TGL tumor cells (106/recipient on day 0$)$. Representative mice are shown. Cross indicates death of all mice in the group of WT T cell recipients. (D) Cumulative incidence of tumor-related death (days $0-100)\left(n=12 / \mathrm{group}, 1 \times 10^{6} \mathrm{~A} 20\right.$ cells/recipient). (E) Cumulative incidence of tumor-related death (days $0-70)\left(n=25-35 / g r o u p, 5 \times 10^{6} \mathrm{~A} 20\right.$ cells/recipient).

labeled BALB/c parental target cells (47). As expected, we observed markedly decreased recovery of CFSE ${ }^{\text {hi }} \mathrm{BALB} / \mathrm{c}$ targets in poly(I:C)treated F1 recipients, consistent with NK-mediated lysis. Pretreatment of the mice with anti-Dll1/Dll4 antibodies had no impact on the elimination of BALB/c targets by NK cells, which remained efficient (Supplemental Figure 10). Thus, Dll1/Dll4 blockade had no effect on the alloresponsive antihematopoietic cell activity of NK cells. Finally, we injected A20 tumor cells in recipients of TCD BM treated with isotype control or anti-Dll1/Dll4 antibodies. Rapid tumor progression is typically observed in this context, consistent with dominant $\mathrm{T}$ rather than NK cell cytotoxicity. We observed no major difference in the survival of control or anti-Dll1/Dll4-treated recipients (Supplemental Figure 11). These findings indicate that any contribution of antitumor NK cell activity in this model is not influenced in a major way by Dll1/Dll4 blockade. In addition, antiDll1/Dll4 antibodies had no direct antitumor effects.

\section{Discussion}

Our findings highlight the therapeutic potential of targeting individual Notch receptors or ligands as a new strategy for controlling GVHD after allo-BMT. We used genetic pan-Notch inhibition as an experimental benchmark to identify nonredundant effects of spe- 
cific Notch receptors and ligands in alloreactive T cells. Notch1 had dominant effects, with a minor contribution from Notch2, while Notch3-4 transcripts were not detectable in donor T cells. Delta-like ligands appeared to account for all the pathogenic effects of Notch in T cells, with dominant effects of Dll4. In terms of efficacy and safety, short-term combined blockade of Dll1/4 Notch ligands with monoclonal antibodies emerged as the most promising strategy to harness the beneficial effects of Notch inhibition after allo-BMT in the preclinical mouse models that we used.

Past work has described redundant roles for Notch1 and Notch2 in $\mathrm{T}$ cells in other immune contexts (48-50). Several reasons could explain the more dominant effects of Notch1 in GVHD. Although both receptors were expressed, Notch2 was less abundant than Notch1 mRNA in alloreactive T cells, especially during peak activation. In addition, Notch1 may preferentially interact with the Dll4 Notch ligand during GVHD. This is reminiscent of the specific requirement for Notch 1 and Dll4 in early $\mathrm{T}$ cell development and neoangiogenesis $(25,32,51)$. It remains to be determined which cells present Dll1/Dll4 ligands to alloreactive $\mathrm{T}$ cells in the post-BMT environment. Moreover, fringe glycosyltransferases could be important because they increase the avidity of Notch receptors for Delta-like as opposed to Jagged ligands $(52,53)$. This mechanism has not been explored in peripheral $\mathrm{T}$ cell immunity, but could account in part for the dominant effects of Delta-like ligands during GVHD.

Early work exploring a role for Notch in alloreactivity relied on Notch ligand overexpression in dendritic cells or in artificial antigen-presenting cells (54-56). This strategy induced hyporesponsiveness of alloreactive $\mathrm{T}$ cells, leading the authors to suggest that Notch might be important in inducing tolerance after transplantation. In contrast, our work indicates that Notch signaling is required for pathogenic functions of alloreactive $\mathrm{T}$ cells in vivo after allo-BMT. This is consistent with a recent report describing delayed organ rejection upon Dll1 inhibition in a model of allogeneic heart transplantation, although our observations identified more profound overall effects of the pathway (57). Our data illustrate the value of studying the effects of Notch signaling in vivo in specific immune responses using loss-of-function approaches. In vitro studies and gain-of-function approaches may not reliably model the physiological and pathophysiological conditions in which $\mathrm{T}$ cells encounter Notch ligands.

Similar to genetic pan-Notch inhibition, Notch1 inactivation or Dll1/Dll4 blockade dramatically decreased production of inflammatory cytokines and GVHD without causing global immunosuppression. Indeed, Notch deprivation preserved in vivo proliferation and increased expansion of alloreactive $\mathrm{T}$ cells in lymphohematopoietic organs. Because proliferation was not changed, enhanced accumulation was likely related to decreased activation-induced $T$ cell death upon Notch inhibition. These findings differ from the effects of most interventions used to control GVHD, including calcineurin inhibitors and many methods that decrease proliferation and expansion of alloreactive $\mathrm{T}$ cells. We also observed long-lasting expansion of donor-derived Tregs, even when D1l1/Dll4 ligands were blocked transiently after allo-BMT. It is possible that these Tregs helped maintain long-term GVHD control upon Notch inhibition. Dll1/Dll4 blockade preserved high levels of cytotoxicity and anticancer activity, although we did observe late relapses in a fraction of the mice when the tumor cell dose was raised to very high levels. Mechanistically, our findings indicate that
Notch blockade has profound effects on the production of inflammatory cytokines that trigger tissue damage and GVHD. In contrast, we have reported previously that expression of the cytotoxic molecules Perforin, Granzyme B, FasL, and Trail was preserved or only modestly decreased in Notch-deprived alloreactive T cells (9). Thus, while we are not suggesting that Notch inhibition completely eliminates GVHD without any effect on GVT activity, our data indicate that GVHD is profoundly reduced while preserving substantial GVT activity, creating a therapeutic window for immunomodulation by Notch inhibition. Furthermore, we found that Dll1/Dll4 inhibition did not affect the alloresponsive antihematopoietic cell activity of NK cells. Interestingly, Yasutomo's group reported that NK cell function could be enhanced by Jagged2 but not Delta-like ligand, suggesting that different Notch ligands have distinct effects on mature NK cells (58). Although more work is needed to fully explore this question, our findings suggest that Dll1/ Dll4 inhibition may preserve NK cell function, an important mechanism underlying the therapeutic effects of human BM transplantation $(37-40,59,60)$.

Our findings identify a promising preclinical strategy of Notch blockade with an improved safety index when compared with systemic pan-Notch inhibition with GSIs. GSIs are currently being explored for their anticancer activity in early clinical trials. Gastrointestinal toxicity has emerged as a significant dose-limiting on-target adverse effect in mice and humans $(28,61,62)$. Concomitant administration of corticosteroids has been reported to decrease gut toxicity in mice (63). However, corticosteroids induce global immunosuppression, which is an unattractive choice after allo-BMT. Intermittent administration schedules are also being tested to improve the safety of GSIs in cancer patients. However, our observations suggest that minimizing gut toxicity of GSIs may be particularly challenging in allo-BMT patients given the heightened requirement for Notch signaling during intestinal regeneration after irradiation, precisely at the time when Notch exerts its effects on alloreactive T cells. Thus, GSIs are not promising agents for therapeutic intervention after allo-BMT.

In steady-state conditions, Notch1 inhibition alone had no or only modest effect on intestinal homeostasis $(24,27)$. In contrast, we observed severe intestinal side effects from isolated Notch1 blockade after allo-BMT. This suggested a heightened requirement for Notch1 after allo-BMT, perhaps during the recruitment of intestinal stem and progenitor cells for intestinal repair after total body irradiation. Radtke and collaborators have observed goblet cell hyperplasia after conditional Dll1 and Dll4 inactivation in the adult intestine (64). However, we did not detect any effect on the gut after antibody-mediated Dll1/Dll4 blockade, both in steadystate conditions and after allo-BMT, indicating preservation of a very useful therapeutic window with these antibodies. The lack of intestinal toxicity with our anti-Dll1/4 antibodies likely results from a dose-dependent effect. Indeed, the anti-Dll1 antibody that we used is an early generation reagent with a relatively low affinity for its target in biochemical assays. Affinity-matured versions of this anti-Dll1 antibody do indeed cause goblet cell hyperplasia and intestinal toxicity, consistent with genetic results (data not shown) (64). Thus, our "low-affinity" anti-Dll1 antibody represents a better reagent with a more desirable therapeutic window in acute GVHD. Radtke and collaborators showed that Dll1 is dominant in the gut (64), while we found that Dll4 is the main driver of acute GVHD, indicating that high-degree Dll4 inhibition with slightly 
less complete Dll1 inhibition could give optimal results in acute GVHD. Furthermore, hematopoietic recovery was not detectably impaired by transient Dll1/Dll4 inhibition. Past work indicates that Notch is not essential for the ultimate recovery of HSCs after transplantation $(23,65,66)$, although Notch2 loss delayed early stages of hematopoietic reconstitution (66). The ligands accounting for these effects in vivo are not known. As we did not observe delayed recovery upon Dll1/Dll4 blockade, this suggests a contribution from Jagged ligands to this effect. Our ability to obtain therapeutic effects in GVHD with short-term Dll1/Dll4 inhibition allows for subsequent efficient thymic recovery upon clearance of anti-Dll4 antibodies. It also decreases concerns about unwanted effects of chronic Notch inhibition that may promote malignancies or perturb normal homeostasis (67-69). However, it remains possible that delayed tissue injury or inflammation (e.g., upon infection) could enhance $T$ cell reactivity and trigger GVHD despite the initial protection provided by transient anti-Dll1/Dll4 blockade. Future work will need to consider this possibility, since our data indicate that Notch inhibition does not lead to complete lasting tolerance of donor $\mathrm{T}$ cells to host alloantigens, as several effector functions (e.g., proliferation, cytotoxicity) remain active. It is also interesting to speculate whether Notch signaling could play a role at late post-transplant stages in delayed acute GVHD or during chronic GVHD, which would open other therapeutic perspectives.

The humanized antibodies that we used in this study were designed to block both mouse and human proteins. Thus, our preclinical work could be efficiently translated into new strategies for GVHD control in clinical trials. Our data point to Notch inhibition as an efficient new strategy to prevent GVHD, while more work is necessary to evaluate its potential to treat ongoing acute or chronic GVHD. Moreover, our work could pave the way toward Notch inhibition in other T cell-mediated disorders, such as organ rejection and autoimmune diseases. Rather than indiscriminate pan-Notch blockade, targeting individual Notch receptors and ligands may be a new approach to bring safe and effective Notchbased therapeutic interventions to the bedside.

\section{Methods}

Mice. BALB/c $\left(\mathrm{H}-2^{\mathrm{d}}\right)$ and $\mathrm{B} 6\left(\mathrm{H}-2^{\mathrm{b}}, \mathrm{CD} 45.2^{+}\right)$mice were from Harlan. C57BL/6.Ptprca (B6-SJL, H-2 $\left.{ }^{\mathrm{b}}, \mathrm{CD} 45.1^{+}\right)$mice were from the National Cancer Institute. ROSA26 $6^{D N M A M L}$ mice (abbreviated DNMAML) contained a Cre-inducible expression cassette encoding the DNMAML-GFP pan-Notch inhibitor under the control of the ROSA26 promoter (20). This allowed for efficient blockade of Notch-mediated transcriptional activation downstream of all Notch receptors and tracking of individual Notch-deprived cells. DNMAML, Notch 1fff (provided by Raphael Kopan, Washington University School of Medicine, St. Louis, Missouri, USA) (70), and Notch2f/f mice (71) were crossed to Cd4-Cre transgenic mice before backcrossing to the $\mathrm{B} 6$ background for more than 8 generations. Notch $1^{f / f} \mathrm{Notch} 2^{f / f} \mathrm{Cd} 4-\mathrm{Cre}^{+}$ mice were used after 4 generations of backcross. Foxp3-IRES-mRFP reporter mice have been described previously (34). Both $\mathrm{Cd} 4-\mathrm{Cre}^{+}$and $\mathrm{Cd} 4-\mathrm{Cr} \mathrm{e}^{-}$agematched B6 mice were included as controls with no difference in outcome.

Pharmacological and antibody-mediated Notch inbibition. The GSI DBZ (EMD Biosciences) was administered in vivo at $10 \mu \mathrm{mol} / \mathrm{kg} / \mathrm{d}$ via i.p. injection (28). Control mice received vehicle only containing DMSO, 0.5\% (w/v) hydroxypropylmethylcellulose (Dow Chemicals), and $0.1 \%(\mathrm{w} / \mathrm{v})$ Tween 80 in water. Humanized IgG1 neutralizing monoclonal antibodies specific for the Notch1- or Notch2-negative regulatory region or for the Dll4 extracellular domain were described previously $(24,25)$. A neutralizing monoclonal antibody specific for Dll1 was generated and tested in a similar fashion. An irrelevant human IgG1 antibody interacting with herpes simplex virus gD protein was used as isotype control. Antibodies were injected i.p. at $5 \mathrm{mg} / \mathrm{kg}$ twice weekly, starting 1 hour before transplantation. In most experiments involving Dll1/Dll4 blockade, only 4 doses were administered (days $0,3,7$, and 10; short course). The quality of each batch was tested in vivo by assessing inhibition of Notch1/Dll4-dependent T cell development and Notch2/Dll1-dependent MZB cells (12, 29, 32, 33).

Induction and assessment of GVHD. Mice underwent allo-BMT as previously described (9). TCD BM was prepared from B6-SJL mice with anti-Thy1.2 antibodies and complement incubation (72). Depletion efficiency was consistently greater than $95 \%$. Suspensions of donor B6 splenocytes were prepared and, where indicated, labeled with $2.5 \mu \mathrm{M}$ CFSE. BALB $/ \mathrm{c}$ recipients were irradiated using $8.5-9$ Gy from a ${ }^{137} \mathrm{Cs}$ source 4 hours before transplantation. We mixed donor B6-SJL TCD BM $\left(4-5 \times 10^{6}\right)$ with or without B6 splenocytes $\left(7-10 \times 10^{6}\right)$ and transplanted this into irradiated BALB/c recipients (8-12 mice per group per experiment). The clinical GVHD score was assessed as described at least weekly (73). Representative photographs were taken at defined time points to document clinical signs of GVHD. In selected experiments, complete blood counts were assessed (Siemens Advia 120 Hematology System). CFU assays were performed using methylcellulose plates and reagents from Stem Cell Technologies. Donor-derived $\mathrm{T}$ cells were tracked in lymphoid organs of recipient mice. Comparison of $\mathrm{T}$ cell numbers between groups was also performed within individual experiments to best account for experimental variability.

Flow cytometry. The following antibodies were from BioLegend: anti$\mathrm{CD} 4$, anti-CD8 $\alpha$, anti-CD19, anti-CD21/35, anti-CD23, anti-CD45.1, antiCD45.2, anti-CD93/AA4.1, anti-B220, anti-TCR $\beta$, anti-H-2Kb, anti-H-2Kd, anti-IFN- $\gamma$, and anti-IL-2. Anti-FoxP3 antibodies were from eBiosciences. Fluorescent conjugates were FITC, phycoerythrin (PE), PE-Cyanin7 (PECy7), allophycocyanin (APC), APC-Cy7, peridinin-chlorophyll-Cy5.5 (PerCPCy5.5). and PE-Texas Red. Biotinylated antibodies were revealed with streptavidin-PE-Cy7, PerCP-Cy5.5, or PE-Texas Red. After blocking unspecific binding with rat/mouse IgG (Sigma-Aldrich), cells were stained in PBS plus $4 \%$ FCS or 1\% BSA. For T cell restimulation, we used plate-bound anti-CD3 (clone 145-2C11) and anti-CD28 (clone 37.51) $(2.5 \mu \mathrm{g} / \mathrm{ml}$ each; Biolegend). Intracellular flow cytometry was performed according to the manufacturer's instructions after addition of Monensin for more than 2 hours (BD). For BrdU incorporation, mice were pulsed with $1 \mathrm{mg} \mathrm{BrdU}$ i.p. 6 hours before euthanasia and staining was performed with a BrdU detection kit (BD). Analysis and sorting were performed on a 3-laser FACSCanto or FACSAria II/III, respectively (BD). Dead cells were excluded with DAPI (Sigma-Aldrich). Files were analyzed in FlowJo (Tree Star).

Quantitative reverse-transcription PCR. RNA was isolated using the RNeasy Micro Kit (QIAGEN). cDNA was prepared with Superscript II (Invitrogen). Real-time PCR was performed with TaqMan or SYBR Green PCR Master Mix and analyzed on a Mastercycler ep realplex (Eppendorf). Relative transcript abundance was calculated using the $\Delta \Delta \mathrm{Ct}$ method after normalization with Hprt1. In some experiments, absolute transcript abundance was measured using a standard titration curve built with known amounts of PCR product as target of amplification. Primer sequences were obtained from the PrimerBank (http://pga.mgh.harvard.edu/primerbank/) or from Applied Biosystems.

In vivo cytotoxicity assay. $\mathrm{BALB} / \mathrm{c}$ allogeneic target splenocytes were labeled with $2.5 \mu \mathrm{M}$ CFSE. Control targets were B6-SJL splenocytes labeled with a low concentration of CFSE $(0.25 \mu \mathrm{M})$. On day 14 , we infused a $1: 1$ mixture of CFSE-labeled BALB/c and B6-SJL targets ( $10^{7}$ cells). Spleens were harvested 18 hours later to assess for the specific killing of CFSE ${ }^{\text {hi }}$ BALB/c target cells by flow cytometry (9). To assess NK cell-mediated cytotoxicity, we used B6 $\times$ BALB/c F1 mice treated with PBS or $200 \mu \mathrm{g}$ 
poly(I:C) (Sigma-Aldrich) 24 hours before i.v. infusion of CFSE ${ }^{\text {lo }} \mathrm{F} 1$ and CFSE ${ }^{\text {hi }} \mathrm{BALB} / \mathrm{c}$ splenocytes $\left(6 \times 10^{6}\right.$ each). Recipient spleens were harvested 16 hours later to evaluate NK cell-mediated elimination of CFSE ${ }^{\text {hi }} \mathrm{BALB} / \mathrm{c}$ target cells by flow cytometry $(46,47)$.

Bioluminescence imaging. A20-TGL (BALB/c, H-2 ) B lymphoma/leukemia cells stably expressing luciferase were provided by Marcel van den Brink (Memorial Sloan-Kettering Cancer Center, New York, New York, USA) (74). Tumor cells were infused on the day of allo-BMT. We anesthetized tumorbearing mice 10 minutes after i.p. injection of $4.5 \mathrm{mg}$ Firefly D-Luciferin potassium salt (Biosynth). We obtained bioluminescent signals using the IVIS200 imaging system (Xenogen). Tumor-related deaths were identified based on the presence of progressive tumor growth on imaging studies, hind leg paralysis, and/or visible tumor at necropsy.

Histological analysis. Adult BALB/c mice were injected with BrdU and tissue collected as described (61). Paraffin sections $(5 \mu \mathrm{m})$ were stained with $\mathrm{H} \& \mathrm{E}$ for general histology and PAS/Alcian blue (Newcomer Supply) to visualize goblet cells. Immunohistochemistry was performed as described (75) with mouse anti-BrdU monoclonal antibody (1:50; Dako) and a biotinylated goat-anti-mouse secondary antibody (1:400; Vector Laboratories). $\mathrm{ABC}$ and $\mathrm{DAB}$ kits (Vector Laboratories) were used per manufacturer instructions, and slides were counterstained with hematoxylin. Analysis of villus height was performed on vehicle and DBZ-treated ileum. Well-oriented crypt-villus units parallel to the plane of section with no evidence of villus truncation were measured (3-6 units/animal) using ImageJ software (1.34u by Wayne Rasband, NIH, USA; http://rsb.info.nih.gov/ij/). BrdU morphometrics was performed on ileums from vehicle, DBZ, isotype control, anti-Notch1, anti-Notch2, anti-Notch1/Notch2, and anti-Dll1/Dll4treated animals (6-10 crypts/animal).

Statistics. Comparison of 2 means was analyzed using 2-tailed unpaired Student $t$ test. Significance was calculated and indicated as
$P<0.05, P<0.01$, or $P<0.001$. Survival in transplant groups was compared using log-rank (Mantel-cox) testing (GraphPad Prism).

Study approval. All experiments were performed according to NIH guidelines and approved by the University of Michigan's Committee on Use and Care of Animals.

\section{Acknowledgments}

We thank Raphael Kopan for providing Notch1f/f mice and Marcel van den Brink for A20-TGL cells. Support for this work was from a Damon Runyon-Rachleff Innovation Award (DRR-05A-09), a Scholar Award of the American Society of Hematology, and the NIH (RO1-AI091627) (to I. Maillard). Individual support included T32 training grants (AI007413-17 to A.R. Sandy; GM07863 and HD007505 to A.J. Carulli; HL007622-26 to C. Ebens, GM007315 to J. Chung), a Miller Fund Award for innovative immunology research (to A.R. Sandy), and trainee research awards from the American Society of Hematology (to G.T. Shan and V. Radojcic). We thank the Department of Radiology at the University of Michigan for the use of the Center for Molecular Imaging which is supported in part by NIH grant P50 CA093990. Flow cytometry was partially supported by a University of Michigan Cancer Center support grant (P30-CA46592).

Received for publication June 24, 2012, and accepted in revised form January 3, 2013.

Address correspondence to: Ivan Maillard, Life Sciences Institute, \#6382A, 210 Washtenaw Avenue, University of Michigan, Ann Arbor, Michigan 48109, USA. Phone: 734.763.3599; Fax: 734.615.5493; E-mail: imaillar@umich.edu.
1. Welniak LA, Blazar BR, Murphy WJ. Immunobiology of allogeneic hematopoietic stem cell transplantation. Annu Rev Immunol. 2007;25:139-170.

2. Wu CJ, Ritz J. Induction of tumor immunity following allogeneic stem cell transplantation. $A d v$ Immunol. 2006;90:133-173.

3. Kolb HJ. Graft-versus-leukemia effects of transplantation and donor lymphocytes. Blood. 2008;112(12):4371-4383.

4. Shlomchik WD. Graft-versus-host disease. Nat Rev Immunol. 2007;7(5):340-352.

5. Ferrara JL, Levine JE, Reddy P, Holler E. Graft-versushost disease. Lancet. 2009;373(9674):1550-1561.

6. Chao NJ, Chen BJ. Prophylaxis and treatment of acute graft-versus-host disease. Semin Hematol. 2006;43(1):32-41.

7. Zeiser R, Beilhack A, Negrin RS. Acute graft-versushost disease-challenge for a broader application of allogeneic hematopoietic cell transplantation. Curr Stem Cell Res Ther. 2006;1(2):203-212.

8. Ho VT, Soiffer RJ. The history and future of T-cell depletion as graft-versus-host disease prophylaxis for allogeneic hematopoietic stem cell transplantation. Blood. 2001;98(12):3192-3204.

9. Zhang $\mathrm{Y}$, et al. Notch signaling is a critical regulator of allogeneic CD4+ T-cell responses mediating graftversus-host disease. Blood. 2011;117(1):299-308.

10. Kopan R, Ilagan MX. The canonical Notch signaling pathway: unfolding the activation mechanism. Cell. 2009;137(2):216-233.

11. Louvi A, Artavanis-Tsakonas S. Notch and disease: A growing field. Semin Cell Dev Biol. 2012; 23(4):473-480.

12. Radtke F, et al. Deficient $T$ cell fate specification in mice with an induced inactivation of Notch1. Immunity. 1999;10(5):547-558.

13. Sambandam A, et al. Notch signaling controls the generation and differentiation of early $\mathrm{T}$ lineage progenitors. Nat Immunol. 2005;6(7):663-670.

14. Tan JB, Visan I, Yuan JS, Guidos CJ. Requirement for Notch1 signals at sequential early stages of intrathymic T cell development. Nat Immunol. 2005;6(7):671-679.

15. Schmitt TM, Zuniga-Pflucker JC. Induction of $\mathrm{T}$ cell development from hematopoietic progenitor cells by delta-like-1 in vitro. Immunity. 2002;17(6):749-756.

16. Osborne BA, Minter LM. Notch signalling during peripheral T-cell activation and differentiation. Nat Rev Immunol. 2007;7(1):64-75.

17. Amsen D, Antov A, Flavell RA. The different faces of Notch in T-helper-cell differentiation. Nat Rev Immunol. 2009;9(2):116-124.

18. Maillard I, Fang T, Pear WS. Regulation of lymphoid development, differentiation and function by the Notch pathway. Annu Rev Immunol. 2005;23:945-974.

19. Radtke F, Fasnacht N, Macdonald HR. Notch Signaling in the immune system. Immunity. 2010;32(1):14-27.

20. Tu L, et al. Notch signaling is an important regulator of type 2 immunity. J Exp Med. 2005; 202(8):1037-1042.

21. Maillard I, et al. Mastermind critically regulates Notch-mediated lymphoid cell fate decisions. Blood. 2004;104(6):1696-1702.

22. Weng AP, et al. Growth suppression of pre-T acute lymphoblastic leukemia cells by inhibition of notch signaling. Mol Cell Biol. 2003;23(2):655-664.

23. Maillard I, et al. Canonical Notch signaling is dispensable for the maintenance of adult hematopoietic stem cells. Cell Stem Cell. 2008;2(4):356-366.

24. Wu Y, et al. Therapeutic antibody targeting of individual Notch receptors. Nature. 2010; 464(7291):1052-1057.

25. Ridgway J, et al. Inhibition of Dll4 signalling inhib- its tumour growth by deregulating angiogenesis. Nature. 2006;444(7122):1083-1087.

26. Wolfe MS. gamma-Secretase in biology and medicine. Semin Cell Dev Biol. 2009;20(2):219-224.

27. Riccio O, et al. Loss of intestinal crypt progenitor cells owing to inactivation of both Notch 1 and Notch2 is accompanied by derepression of CDK inhibitors p27Kip1 and p57Kip2. EMBO Rep. 2008;9(4):377-383.

28. Van Es JH, et al. Notch/gamma-secretase inhibition turns proliferative cells in intestinal crypts and adenomas into goblet cells. Nature. 2005;435(7044):959-963.

29. Saito T, et al. Notch2 is preferentially expressed in mature $B$ cells and indispensable for marginal zone $B$ lineage development. Immunity. 2003;18(5):675-685.

30. Amsen D, Blander JM, Lee GR, Tanigaki K, Honjo $\mathrm{T}$, Flavell RA. Instruction of distinct CD4 T helper cell fates by different notch ligands on antigenpresenting cells. Cell. 2004;117(4):515-526.

31. Ladi E, et al. The divergent DSL ligand Dll3 does not activate Notch signaling but cell autonomously attenuates signaling induced by other DSL ligands. J Cell Biol. 2005;170(6):983-992.

32. Koch $U$, et al. Delta-like 4 is the essential, nonredundant ligand for Notch 1 during thymic $\mathrm{T}$ cell lineage commitment. J Exp Med. 2008;205(11):2515-2523.

33. Hozumi K, et al. Delta-like 1 is necessary for the generation of marginal zone B cells but not $\mathrm{T}$ cells in vivo. Nat Immunol. 2004;5(6):638-644.

34. Wan YY, Flavell RA. Identifying Foxp3-expressing suppressor T cells with a bicistronic reporter. Proc Natl Acad Sci U S A. 2005;102(14):5126-5131.

35. Bernstein ID, Boyd RL, Van Den Brink MR. Clinical strategies to enhance posttransplant immune reconstitution. Biol Blood Marrow Transplant. 2008;14(1 suppl 1):94-99. 
36. Na IK, et al. The cytolytic molecules Fas ligand and TRAIL are required for murine thymic graft-versushost disease. J Clin Invest. 2010;120(1):343-356

37. Albi N, et al. Natural killer (NK)-cell function and antileukemic activity of a large population of CD3+/CD8+ T cells expressing NK receptors for major histocompatibility complex class I after "three-loci" HLA-incompatible bone marrow transplantation. Blood. 1996;87(9):3993-4000

38. Aversa F, et al. Treatment of high-risk acute leukemia with T-cell-depleted stem cells from related donors with one fully mismatched HLA haplotype. NEngl J Med. 1998;339(17):1186-1193.

39. Hsu KC, et al. Improved outcome in HLA-identical sibling hematopoietic stem-cell transplantation for acute myelogenous leukemia predicted by KIR and HLA genotypes. Blood. 2005;105(12):4878-4884.

40. Venstrom JM, et al. HLA-C-dependent prevention of leukemia relapse by donor activating KIR2DS1. NEngl J Med. 2012;367(9):805-816.

41. Weisdorf D, et al. T cell-depleted partial matched unrelated donor transplant for advanced myeloid malignancy: KIR ligand mismatch and outcome. Biol Blood Marrow Transplant. 2011;18(6):937-943.

42. Cudkowicz G, Bennett M. Peculiar immunobiology of bone marrow allografts. II. Rejection of parental grafts by resistant F 1 hybrid mice. J Exp Med. 1971:134(6):1513-1528.

43. Cudkowicz G, Stimpfling JH. Induction of immunity and of unresponsiveness to parental marrow grafts in adult F-1 hybrid mice. Nature. 1964;204:450-453.

44. Kiessling R, Hochman PS, Haller O, Shearer GM Wigzell H, Cudkowicz G. Evidence for a similar or common mechanism for natural killer cell activity and resistance to hemopoietic grafts. Eur J Immu nol. 1977;7(9):655-663.

45. Dennert G, Anderson CG, Warner J. T killer cells play a role in allogeneic bone marrow graft rejection but not in hybrid resistance. J Immunol. 1985;135(6):3729-3734.

46. Ogasawara K, Benjamin J, Takaki R, Phillips JH, Lanier LL. Function of NKG2D in natural killer cell-mediated rejection of mouse bone marrow grafts. Nat Immunol. 2005;6(9):938-945

47. Patel R, Belanger S, Tai LH, Troke AD, Makrigiannis AP. Effect of Ly49 haplotype variance on NK cell function and education. J Immunol. 2010;185(8):4783-4792.

48. Amsen D, et al. Direct regulation of Gata3 expres- sion determines the $\mathrm{T}$ helper differentiation potential of Notch. Immunity. 2007;27(1):89-99.

49. Tacchini-Cottier F, Allenbach C, Otten LA, Radtke F. Notch1 expression on $\mathrm{T}$ cells is not required for CD4+ T helper differentiation. Eur J Immunol. 2004;34(6):1588-1596.

50. Tacchini-Cottier F, et al. An immunomodula tory function for neutrophils during the induction of a CD4(+) Th2 response in BALB/c mice infected with Leishmania major. J Immunol. 2000;165(5):2628-2636.

51. Noguera-Troise I, et al. Blockade of Dll4 inhibits tumour growth by promoting non-productive angiogenesis. Nature. 2006;444(7122):1032-1037.

52. Visan I, Tan JB, Yuan JS, Harper JA, Koch U, Guidos CJ. Regulation of T lymphopoiesis by Notch 1 and Lunatic fringe-mediated competition for intrathymic niches. Nat Immunol. 2006;7(6):634-643.

53. Besseyrias V, et al. Hierarchy of Notch-Delta interactions promoting $\mathrm{T}$ cell lineage commitment and maturation. J Exp Med. 2007;204(2):331-343.

54 . Hoyne GF, et al. Serrate1-induced notch signalling regulates the decision between immunity and tolerance made by peripheral CD4(+) T cells. Int Immunol. 2000;12(2):177-185.

55. Yvon ES, et al. Over expression of the Notch ligand, Jagged-1 induces alloantigen-specific human regulatory T cells. Blood. 2003;102(10):3815-3821.

56 . Wong KK, et al. Notch ligation by Delta1 inhibits peripheral immune responses to transplantation antigens by a CD8+ cell-dependent mechanism. J Clin Invest. 2003;112(11):1741-1750.

57. Riella LV, et al. Blockade of Notch ligand delta 1 promotes allograft survival by inhibiting alloreactive Th1 cells and cytotoxic T cell generation. J Immunol. 2011;187(9):4629-4638.

58. Kijima M, et al. Dendritic cell-mediated NK cell activation is controlled by Jagged2-Notch interaction. Proc Natl Acad Sci US A. 2008;105(19):7010-7015

59. Ruggeri L, et al. Role of natural killer cell alloreactivity in HLA-mismatched hematopoietic stem cell transplantation. Blood. 1999;94(1):333-339.

60. Velardi A, Ruggeri L, Mancusi A. Killer-cell immunoglobulin-like receptors reactivity and outcome of stem cell transplant. Curr Opin Hematol. 2012;19(4):319-323.

61. Vandussen KL, et al. Notch signaling modulates proliferation and differentiation of intestinal crypt base columnar stem cells. Development. 2012;139(3):488-497.
62. Cullion K, et al. Targeting the Notch 1 and mTOR pathways in a mouse T-ALL model. Blood. 2009;113(24):6172-6181.

63. Real PJ, et al. Gamma-secretase inhibitors reverse glucocorticoid resistance in T cell acute lymphoblastic leukemia. Nat Med. 2009;15(1):50-58.

64. Pellegrinet L, et al. Dll1- and dll4-mediated notch signaling are required for homeostasis of intestinal stem cells. Gastroenterology. 2011;140(4):1230-1240.

65. Gao J, et al. Hedgehog signaling is dispensable for adult hematopoietic stem cell function. Cell Stem Cell. 2009;4(6):548-558.

66. Varnum-Finney B, Halasz LM, Sun M, Gridley T, Radtke F, Bernstein ID. Notch2 governs the rate of generation of mouse long- and shortterm repopulating stem cells. J Clin Invest. 2011; 121(3):1207-1216

67. Klinakis A, et al. A novel tumour-suppressor function for the Notch pathway in myeloid leukaemia. Nature. 2011;473(7346):230-233.

68. Liu Z, et al. Notch 1 loss of heterozygosity causes vascular tumors and lethal hemorrhage in mice. J Clin Invest. 2011:121(2):800-808.

69. Yan M, et al. Chronic DLL4 blockade induces vascular neoplasms. Nature. 2010;463(7282):E6-7.

70. Yang X, Klein R, Tian X, Cheng HT, Kopan R, Shen $\mathrm{J}$. Notch activation induces apoptosis in neural progenitor cells through a $\mathrm{p} 53$-dependent pathway. Dev Biol. 2004;269(1):81-94.

71. Mccright B, Lozier J, Gridley T. Generation of new Notch2 mutant alleles. Genesis. 2006;44(1):29-33.

72. Luznik L, Jalla S, Engstrom LW, Iannone R, Fuchs EJ. Durable engraftment of major histocompatibility complex-incompatible cells after nonmyeloablative conditioning with fludarabine, low-dose total body irradiation, and posttransplantation cyclophosphamide. Blood. 2001; 98(12):3456-3464.

73. Cooke KR, et al. An experimental model of idiopathic pneumonia syndrome after bone marrow transplantation: I. The roles of minor $\mathrm{H}$ antigens and endotoxin. Blood 1996:88(8):3230-3239.

74. Zakrzewski JL, et al. Adoptive transfer of T-cell precursors enhances $\mathrm{T}$-cell reconstitution after allogeneic hematopoietic stem cell transplantation. Nat Med. 2006;12(9):1039-1047.

75. Lopez-Diaz L, et al. Parietal cell hyperstimulation and autoimmune gastritis in cholera toxin transgenic mice. Am J Physiol Gastrointest Liver Physiol. 2006;290(5):G970-G979. 